\title{
MASTER IIFRL15233
}

\section{THE ROLE OF RADIATION DAMPING IN THE IMPEDANCE FUNCTION APPROACH TO SOIL-STRUCTURE INTERACTION ANALYSIS}

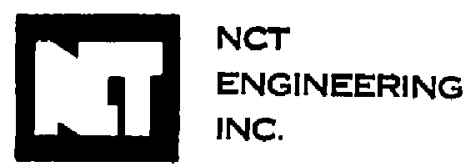

May 1980

Prepared by: NCT Engineering, Inc.

For: University of California, Lawrence Livermore Laboratory

Under: Personal Services Agreement 2619600 


\section{DISCLAIMER}

This book was prepared as an account of work sponsored by an agency of the United States Government. Neither the United States Govermment nor any agency thereof, nor any of their employees, makes any warranty, expressed or impiied, or assumes any legal liability or responsibility for the accuracy, completeness, or usefulness of any information, apparatus, product, or process disclosed, or represents that its use would not infringe privately owned rights. Reference herein to any specific commercial product, process, or service by trade name, trademark, manufacturer, or otherwise, does not necessarily constitute or imply its endorsement, recommendation, or favoring by the United States Government or any agency thereof. The views and opinions of authors expressed herein do not necessarily state or reflect those of the United States Government or any agency thereof.

This work was supported by the United States Nuclear Regulatory Commis', Ion under a Memorandum of Understanding with the United States Department of Energy. 


\title{
THE ROLE OF RADIATION DAMPING IN THE IMPEDANCE FUNCTION APPROACH TO SOIL-STRUCTURE INTERACTION ANALYSIS
}

\author{
Prepared for University of California, \\ Lawrence Livermore Laboratory \\ P.0. BOX 308 \\ Livermore, Califomia 94550 \\ Under Personal Services Agreement 26196010
}

\author{
Prepared by \\ NCT Engineering, Inc. \\ 3650 Mt. Diablo Blvd. Suite 190 \\ Lafayette, California 94549
}

May 1980

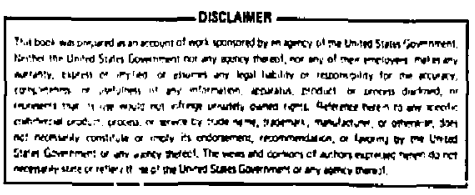


This report was prepared by N. C. Tsai of NCT Engineering, Inc., for the Lawrence Livermore Laboratory (LLL). It is intended to clarify certain technical issues in the analytical treatment of soil-structure interactions. These issues arose during the limited reanalyses of the Oyster Creek and Palisades Nuclear Power Plants that LLL is conducting for the U.S. Nuclear Regulatory Commission (NRC) as part of the Systematic Evaluation Program (SEP). The RRC FIN No. is A-0233, and the technical monitor is H. A. Levin.

The report is intended for use by the SEP's Senior Seismic heview Team in formulating recomendations on the treatment of damping in soil-structure interaction analysis. It has been technically reviewed by SEP program leaders R. C. Murray and T. A. Nelson at LLL.

The author wishes to thank Shelly Calvert for typing the final manuscript and R. K. Johnson of EG\&G/San Ramon Operations for editing assistance. 
This report was prepared at the request of the Lawrence Livermore Laboratory (LLL) to provide background information for analyzing soil-structure interaction by the frequency-independent impedance function approach. LLL is conducting such analyses as part of its seismic review of selected operating plants under the Systematic Evaluation Program for the U.S. Nucl ear Regulatory Commission. The analytical background and basic assumptions of the impedance function theory are briefly reviewed, and the role of radlation damping in soil-structure interaction analysis is discussed. The validity of modeling soil-structure interaction by using frequency-independent impedance functions is evaluated based on data from several field tests. Finally, the recommended procedures for performing soil-structure interaction analyses are discussed with emphasis on the modal suporposition method. 


$$
\mathrm{C}_{\mathrm{x}}, \mathrm{C}_{\mathrm{r}}, \mathrm{C}_{\mathrm{v}}
$$$$
D_{x}, D_{r}, D_{v}
$$$$
x_{x}, k_{p}, k_{v}
$$

$$
C_{x x}(\omega), C_{r r}(\omega)
$$$$
k_{x x}(\omega), k_{r r}(\omega)
$$$$
\beta_{j}, \omega_{j}
$$

$$
\bar{\beta}_{k}, \bar{\omega}_{k}
$$

B

G

$$
V_{s}
$$

Frequency-independent radiation damping coefficients for lateral translation, rocking and vertical translation of the base.

Radiation damping ratios based on $C_{x}, C_{r}$, and $\mathrm{C}_{v}$, respectively.

Frequency-independent impedance springs for lateral translation, rocking and vertical translation of the base.

Frequency-dependent radiation damping coefficient for lateral translation and rocking of the base.

Frequency-dependent impedance springs for lateral translation and rocking of the base.

Percentage of critical damping and natural frequency, respectively, of the $j$-th mode of the fixed base structure.

Composite modal damping and natural frequency, respectively, of the k-th mode of the soil-structure interaction system.

Gravitational acceleration.

Shear modulus of foundation soil.

Shear wave velocity of Ioundation soll.

Gircular frequency (radian/sec). 
1. Introduction 1-1

2. The Impedance Function Approach 2-1

3. Radiation Damping 3-1

3.1 Radiation Damping as a Damping Ratio 3-1

3.2 The Effect of Radiation Dampine 3-3

4. Response Analysis by the Method of Modal Superposition 4-1

4.1 Limilations 4-1

4.2 Composite Modal Damping 4-2

4.2.1 Determination of Composite Modal Damping 4-2

4.2.2 The Proper Role of Composite Modal Damping 4-3

4.3 Case Study 4-4

5. Evaluation of Field Tests 5-1

5.1 Case I - Hamaoka No. 1 BWR Reactor Building 5-1

5.2 Case II - Hamaoka No.'s 1 \& BWR Reactor Building 5-3

5.3 Case III - Nucl ear Saf ety hesearch Center Building 5-4

5.4 Case IV - Concrete Slab Field Tests at SONGS 2 \& Sites 5-5

5.5 Case V - Harmonic Vibration Tests on a Steel Body 5-7

6. Summary and Conclusions 6-1

6.1 Validity of the Frequency-Independent Impedance Approach 6-1

6.2 The Effect of Radiation Damping on Structural Response 6-2

6.3 Analysis Procedure $6-2$

7. References 7-1 
In the seismic analysis of structures, the soil-struature interaction effect may be accounted for by either the imptdance function or the finite element approach. Both methods have advantages and limitations. Nevertheless, the state of the art indicates that both approaches share the same theoretical basis--specifically, both recognize that geometric radiation damping should be placed where the soil foundation is cut off from the soil-structure systen. In the impedance approach, radiation damping is simulated by attaching to the structural base some frequency-dependent dampers or, if the approximation suffices, frequency-independent dampers. For the finite element approach, radiation damping is simulated by a series of dampers placed al ong the soil cut-off boundaries (e.g., Refs. 1, 2, 3, 4).

Unlike material internal damping, radiation damping is not an inherent material property. It is one of the parameters required to represent those soil media that are excluded from the soil-structure interaction model under consideration. Its analytical derivation is based on the assumption that the excluded soil media extended to a semirinfinite half space. In view of the relative dimensional difference between the earth and typical buildings, one may say that the half-space representation of the earth is fairly reasonable.

Note that the radiation damping concept has al ready been used in seismic prospecting and in investigating the influence of local soil deposits on earthquake ground motions (e.8., Hers. 5 and 6). Thus, it is a recognized way to account for the spatial dissipation of energy in a soil medium.

Over the last several years use of radiation damping in soil-structure interaction problems has gained acceptance by engineers. Much confusion still exists, however, for the following reasons:

- Many engineers do not have the background necessary to really understand the mechanism of radiation damping and to cor uctly apply the rather abstract concept to soil-structure interaction analyses. Radiation damping is of ten mistakenly perceived as a kind of material damping.

- It is generally held that the larger the radiation damping, the lower will be the structural response. As a consequence, limiting values on the magnitude of the radiation damping have been stipulated. Such confusion occurs because the actual effect of radiation damping on the structural response is seldow understood properly. As will be illustrated later in this report, an increase in radiation damping does not necessarily lead to a decrease in structural response. 
- Data from dynamic tests of buildings and foundations provide the only realistic way to test the validity of soil-structure interaction theory. However, such data can of ten be misinterpreted. For example, one set of test data can lead to different conclusions depending on how the data are interpreted.

- Additional confusion arises in the simpi: case in which soll-structure interaction is represented by frequency-independent impedance functions. This is because most engineers use the method of modal superposition (also referred to as modal analysis or the normal mode method) to solve the equations of motion, but few realize that:

- Modal superposition gives only approximate solutions; the rigorous solution must be obtained by such methods as Fourier transformation or direct integration.

- The computed structural response may vary appreciably with the technique chosen for determining the composite modal damping.

- Modal superposition is inapplicable, no matter what modal damping values are used, for cases in which the radiation damping is sufficiently large. This will be illustrated later in the report.

Such gisunderstandings lead many engi neers to stipulate a limiting value for the composite modal damping, giving rise to yet another controversy. This report is intended to review the impedance function approash and the significance of radiation damping in soil-structure interaction analyses and, thereby, to clarify the issues described above. To accomplish these objectives, the report is organized as follows:

- Brief review of the essence of the impedance function representation for a foundation.

- Discussion of the effect of radiation damping on structural response. - Discussion of the limitations of the modal superposition method and the proper view of the role of composite modal damping in the analysis.

- Evaluation of the avallable dynamic field test data and their correlation with theory. 
For a structure founded at the surface of a site that is idealized as an elastic, horizontally layered half space (Fig. 2-1(a)), the half-space foundation may be aralytically represented by a set of comp:ax, rrequency-dependent impedance functions. In essence, the impeciance functions relate the structural base shear and moment- $y_{b}(t)$ and $M_{b}(t)$, respectively-m to the base motions as follows

$$
\left\{\begin{array}{l}
V_{b}(t) \\
M_{b}(t)
\end{array}\right\}=\left[\begin{array}{ll}
R_{x x}(\omega)+1 r_{x x}(\omega) & R_{x p}(\omega)+I_{x r}(\omega) \\
F_{r x}(\omega)+1 I_{r x}(\omega) & R_{r r}(\omega)+I_{r r}(\omega)
\end{array}\right]\left\{\begin{array}{l}
x_{b}(t) \\
r_{b}(t)
\end{array}\right\}
$$

where $x_{b}$ is the base translation relative to the free-field motion, and $r_{b}$ is the base rotation.

The impedance functions are frequencymdependent because the soil mass is included in the terivation. The imaginary parts in the impedance matrix exist because of the assumption that certain refracted seismic waves propagate into the semi-infinite space and do not returt; they vanish identically if, instead, a perfectily rigid boundary is assumed to exist somewhere in the half-space soil roundation. The off-diagonal terms are usually small and, as a simplification, may be ignored. As a mechanical analogy, the simplified impedance matrix nay be translated into a set of frequency-dependent springs and dampers by letting

$$
\begin{array}{ll}
R_{x x}(\omega)=K_{x x}(\omega) & I_{x x}(\omega)=\omega c_{x x}(\omega) \\
R_{r r}(\omega)=k_{r r}(\omega) & t_{r r}(\omega)=r_{r p}(\omega)
\end{array}
$$

Thus, the simplified Eq. (2-1) can be rewritten (Ref. 7) as

$$
\left[\begin{array}{l}
V_{b}(t) \\
M_{b}(t)
\end{array}\right\} \equiv\left[\begin{array}{ll}
K_{x x}(\omega) & \\
& K_{r r}(\omega)
\end{array}\right]\left[\begin{array}{l}
x_{b}(t) \\
\Gamma_{b}(t)
\end{array}\right]+\left[\begin{array}{ll}
c_{x x}(\omega) & \\
& c_{r r}(\omega)
\end{array}\right]\left[\begin{array}{l}
\dot{x}_{b}(t) \\
\dot{r}_{b}(t)
\end{array}\right\}
$$

This results in the equivalent soll-structure systens shom in Fig. 2-1(b), in which the Inpedance runctions $K_{w v}$ and $C_{v v}$ are for vertical vibrations.

When the soil profiles permit a uniform half-space Idealization of the site, the frequency-dependent parameters may be further approximated by 
f requency-independent ones (Ref. 7). That is, Eq. (2-3) may be further simplified for a uniform si te:

$$
\left[\begin{array}{l}
V_{b}(t) \\
H_{b}(t)
\end{array}\right] \equiv\left[\begin{array}{ll}
K_{x} & \\
& K_{r}
\end{array}\right]\left[\begin{array}{l}
x_{b}(t) \\
r_{b}(t)
\end{array}\right]+\left[\begin{array}{ll}
c_{x} & \\
& c_{r}
\end{array}\right]\left\{\begin{array}{l}
\dot{x}_{b}(t) \\
\dot{r}_{b}(t)
\end{array}\right\}
$$

Because of the approximation, the values of $K_{x^{\prime}}, \ldots, C_{r}$ may vary somewhat, depending on the choice of the individual engineer. A popular choice is that suggested by Richart, Hall, and Hoods (Ref, 8), Tables 2-1 an 2-2 show their values for circular and rectangular bases, respectively.

Several important featur as of the imprdance functions are summarized below.

(a) The impedance functions are analytically derived on the assumptions that the structural base is rigid and that a perfect bond exists between the base and the soil foundation. For actual building baces that have a large ratio of horizontal dimension to thickness, the rigid-base assumption may be questionable. However, the "box" or "framing" effect of those structural walls extending down to the base tends to increase base rigidity. In other words, the base slab within a building system is actually more flexuraily rigid than if the base slab alone is placed on the soil foundation. Such an observation has typically been demonstrated by finite element soil-structure interaction analyses for which no rigid-base assumption is necessary.

(b) As pointed out above, the equivalent damping terms in the impedance functions stem from the imaginary parts that exist because of the wave radiation assumption in the theory. Therefore, they should not be construed as material damping.

(c) The impedance functions represent the equivalent boundary conditions required to replace the entire half-space foundation that is excluded from the model along the soil-structure interface. In the event that the balf-space foundation is cut off somewhere away from the base-such as in the finite element approach--the impedance functions required along tive cut-off boundary to replace the excluded portion of the foundation become those described in Ref. 1. The soil-structure system shown in 
Fig. 2-? $\{$ i, therefore, is mathematically identical to those in Figs. 2-1(a) and (b). This illustrates the statement made in the Introduction that boih the impedance and the finite element approaches share the same theoretical basis-the half-space assumption.

(d) The effect of soil material damping nay be accounted for in the impedance functions through analytical derivations (Refs. 9, 10). The soil damping mechanism may be viscous or hysteretic.

Inclusion of the material damping modifies both the spring and the damping terms, al though, as one would anticipate, th. effect on the latter is more pronounced. The equivalent damping terms now contain the composite effects from both the radiation damping and the material damping.

(e) Rigorous analytical solutions are not available yet to account for the effect of structural embedment. Approxinate solutions, however, have been suggested (e.g., Refs. 10, 11). In general, embedment tends to increase the values of botit the spring and the damping terms. 
TABLE 2-1. Frequency-independent impedance functions for circular bases (from Ref. 8).

\begin{tabular}{|c|c|c|}
\hline Motion & $\begin{array}{c}\text { Equivalent } \\
\text { Spring Constant }\end{array}$ & $\begin{array}{c}\text { Equivalent } \\
\text { Damping Coef } f \text { icient }\end{array}$ \\
\hline Horizontal & $K_{X}=\frac{32(1-v) G R}{7-B v}$ & $G_{x}=0.576 \mathrm{~K}_{x} R \sqrt{\rho / G}$ \\
\hline Rocking & $K_{r}=\frac{8 G R^{3}}{3(1-v)}$ & $C_{r}=\frac{0.30}{1+B_{\psi}} K_{x} R \sqrt{\rho / G}$ \\
\hline Vertisal & $K_{v}=\frac{4 G R}{1-v}$ & $C_{V}=0.85 K_{V}^{R} \sqrt{0 / G}$ \\
\hline
\end{tabular}

$v=$ Poisson's ratio of foundation medium,

G a shear modulus of foundation medium,

$R$ = radius of the circular base mat,

$\rho=$ density of foundation medium,

$B_{\psi}=\frac{3(1-\nu) I_{0}}{\theta_{\rho} R^{5}}$

$I_{0}=$ total mass moment of inertia of structure and base mat about the rocking axis at the base. 
TABLE 2-2. Frequency-independent impedance functions for rectangular bases (frow Ref. B).

\begin{tabular}{|c|c|c|}
\hline Motion & $\begin{array}{c}\text { Equivalent } \\
\text { Spring Constant }\end{array}$ & $\begin{array}{c}\text { Equivalent } \\
\text { Damping Coefficient }\end{array}$ \\
\hline Horizontal & $K_{x}=2(1+v) G B x^{\sqrt{B E}}$ & $R_{x}=\sqrt{B L / 7}$ \\
\hline Rocking & $K_{r}=\frac{G}{L-v} G_{\psi} B^{2} L$ & $B_{r}=\sqrt[4]{B^{3} L / 3 \pi}$ \\
\hline vertical & $K_{v}=\frac{G}{1-v} \quad B_{2} \sqrt{B L}$ & $R_{v}=\sqrt{B I / \pi}$ \\
\hline
\end{tabular}

* The equivalent radius, $R_{x}, R_{p}$ or $R_{y}$ is for computing the radiation damping $C{ }^{\prime}{ }{ }_{r} x^{\prime}{ }^{\prime} E_{w}$, respectively, using the
Table $2-1$.

\author{
$B=$ width of the base mat in the plane of \\ horizontal excitation; \\ $I=$ lengih of the base mat perpendicular to the \\ plane of horizontal excitation:
}
$B_{X}, B_{\psi}, B_{Z}=$ constants that are functions of the dimen- sional ratio, B/L. (After Fig. 10-16 in Ref.8)

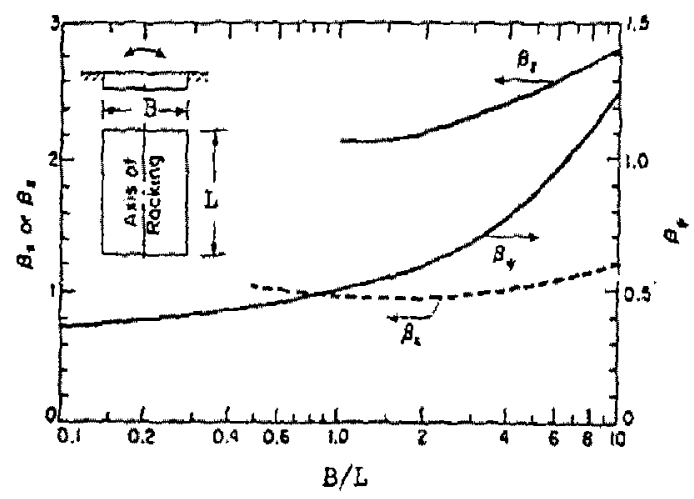


(a) Building on An Elastic, Layered Half Space

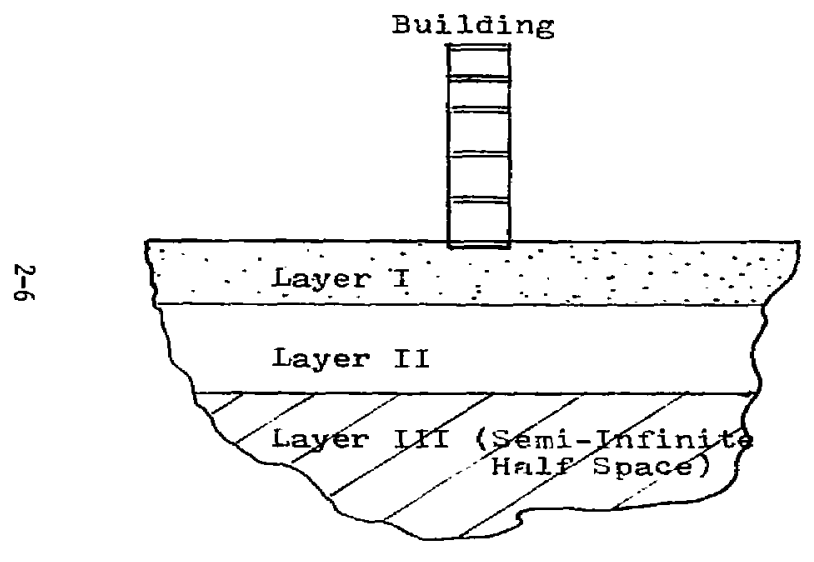

(b) Building with Impedance runctions fiepresenting the Entire Layered half space (c) Building Nith Part of Soil Foundation Included in the Model and Fiadiation Darping Along Cutoff Boundary

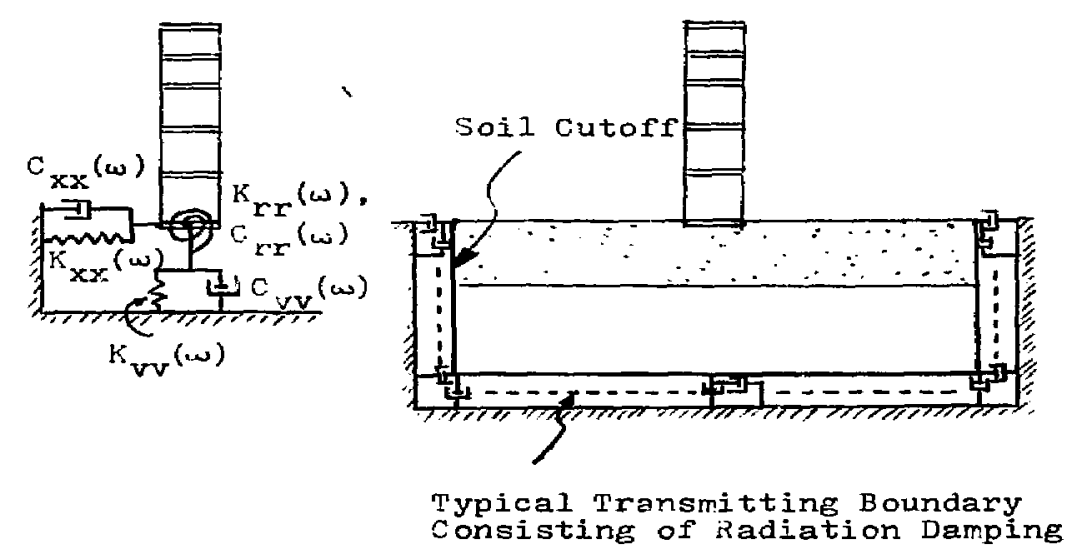

Fig. 2-1 The Three rathematically Equivalent Soil-Structure Systems 


\section{RADIATION DAMPING}

This section details the pitfalls of expressing radiation damping in terms of a damping ratio that is then used to predict the effect of radiation damping on structural response. A simple illustrative example of a one-mass structure is presented.

\subsection{RADIATION DAMPING AS A DAMPING RATIO}

It is common engineering practice to convert the radiation damping coefficient that is derived from theory into a certain damping ratio in order to predict its effect on the structural response. This practice may have begun because engineers are familiar with the concept of the modal damping ratio as a convenient measure of the effect of material damping in a structural system subjected to dynamic loadings. There are severai pitfalls associated with treating radiation damping the same way, and few engineers actually know about them. These pitfalls are discussed below.

(a) To convert the radiation damping coerficieat, say $C_{x}$, into a dampins ratio requires a certain definition such as

$$
D_{x}=C_{x} / 2 \sqrt{k m}
$$

This definition applies only to single-degree-of-f reedoin (SDOF) systems having uniquely specified values of $m, c$, and $k$, and it has certain physical meaning. A question hence arises: what $k$ and $m$ must be used in Eq. (3-1) for a soil-structure system? There is no unique answer to this question; hence, the value of $D_{x}$ will vary depending on the engineer's choice. Although one common practice is to use $k=k_{x}$ and $n=$ total structural mass, the $D_{x}$ so computed has no particular physical signisicance unless the struture is so stiff relative to $\mathrm{K}_{x}$ that it may be regarded as a rigid body, and the entire interaction system may be vieked as a SDOF system.

In short, not only does $D_{x}$ have no unique definition, it generally has no particular physical meaning. Thus, misunderstanding and misuse of the radiation damping concept can easily happen whenever it is thought of only in terms of the damping ratio. 
(b) Not realizing that the theory provides only the radiation damping coefficient from which the damping ratio must be computed, many engineers infer that structures with similar geometry and founded on similar soils have similar values of radiation damping ratios for soil-structure interaction analyses. The pitfall is apparent: it is the radiation damping coefficients that would have similar values. Consider the conditions shown in Fig. 3-1. For Case (a), which consists of the basemat alone, assume that $D_{x}$ equals $18 \%$ as predicted by the theory or measured from dynamic tests. According to the theory, the value of the radiation damping coefficient, $C_{x}$, w1ll remain the same for all three cases. Applying Eq. (3-1) to convert to a damping ratio and using the conventional practlce of $k=k_{x}$ and $m=$ the total structural mass, one would find that the same $C_{x}$ results in the following $D_{x}$ values:

$$
\begin{aligned}
& D_{x}=18 \% \sqrt{4}=9 \% \quad \ldots \ldots \ldots \ldots \text { Case }(b) \\
& D_{x}=18 \% \sqrt{9}=6 \$ \quad \ldots \ldots \ldots \text { Case }(c) .
\end{aligned}
$$

Note that $\mathrm{K}_{\mathrm{x}}$ remains unchanged for all three cases, according to the theory; hesce, $D_{x}$ is inversely proportional to the total structural mass in this example. To infer that all three cases have the same value of $D_{x}=18 \%$ is apparently erroneous.

(c) Many engineers take $D_{x}$ to be a modal damping ratio to predict how radiation damping affects structural response. This misunderstanding will be clarified in Sec. 3.2.

(d) As mentioned in the Introduction, engineers of ten resort to modal superposition for the numerical solution in analyzing uniform soil sites, for which the impedance functions are approximate frequency-independent functions. Certain composite modal damping values must then be determined, and computational techniques have been developed that are formulated only in terms of the radiation damping ratio, not the damping coefficient. The pitfall associated with adopting such techniques to calculate composite modal damping will be discussed in Sec. 4. 


\subsection{THE EFFECT OF RADIATION DAMPING}

It is generally held that large radiation damping results in low structural response. Such is not necessarily true, and the i?lusion stems from a misunderstanding of the actual role of radiation damping. To illustrate this point, consider one simple example--a two-mass, spring-and-damper-connected system undergoing vertical harmonic vibrations as depicted in Fig. 3-2. The system may be regarded as a soil-structure $\because$ ation syster composed of a one-mass structure $\left(m_{1}\right)$, the base $\left(m_{2}\right)$, te frequency-independent impedance functions $k_{2}$ and $c_{2}$. The structural frequency is $5 \mathrm{~Hz}$, and structural damping is $2 \%$ of critical (see Fig. 3-2). Let $c_{2}$, the radiation damping in this case, be a variable which, when converted to the dimensionless parameter $D_{2}$ according to Fig. 3-2, assumes the values of $0.1,0.5,1,2,5$ and 10 . When subjected to harmonic, vertical, input ground mation of $\ddot{u}_{g}(t)=\sin \omega t$, the amplitude of the steady-state response of $m_{1}$ is that shown in Fig. 3-3 (Ref. 12). Note the following observations.

- The response amplitude of $m$ indeed decreases as $D_{2}$ increases from 0.1 to 0.5 to 1.0 , hut then it increases again for higher values of $D_{2}$. - The resonant frequency of the system, which is dictated by the location of the peak frequency for the amplitude curve of $m_{q}$, shifts from $3.8 \mathrm{~Hz}$ (the first frequency of the undamped system) to $5 \mathrm{~Hz}$ (the fixed-base-structure frequency) as $D_{2}$ increases from 0.1 to 10.0 . This is so because the dynamic response of $m_{1}$ approaches that of the fixed-base struriure as $D_{2}$ becomes large. In the limiting case $\left(D_{2}\right.$ becomes infinite), the structure becomes dynamically fixed at the base because of the infinite damping force, even thoygh spring $k_{2}$ has $\mathrm{mly}$ a finite value. In other words, the amplitude curve of $m_{1}$ for $D_{2}$ equals infinity will be identical to that of the fixed-base structure having a damping of $2 \%$ critical.

The point to be made here is that the radiation demping ratio is merely a dimensionless quantity and, unlike the modal damping, cannot be used to predict the magnitude of the structural response. The example clearly demonstrates another important point: arbitrarily reducing the magnitude of the radiation damping for any given problem for fear that the structural response might be underestimated does not necessarily produce a more 
conservative structural response. Besides, such a reduction may result in a sloor spectrum that has peaks at erroneous frequencies. For instance, assume that the theoretical value of $D_{2}$ is actially 10 in the example problem. If this value is drastically reduced to 0.1 , the response of $m_{1}$ would not increase drastically as many would anticipate. Actually, the response of $\boldsymbol{m}_{\hat{i}}$ decreases slightly. Also, the resonant frequency is in error (3.8 rather than $5.0 \mathrm{~Hz})$. 


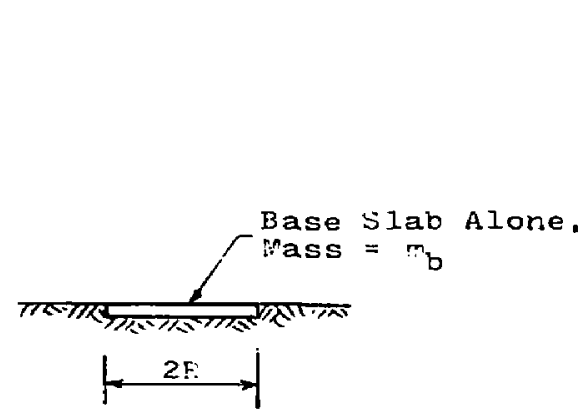

(a)

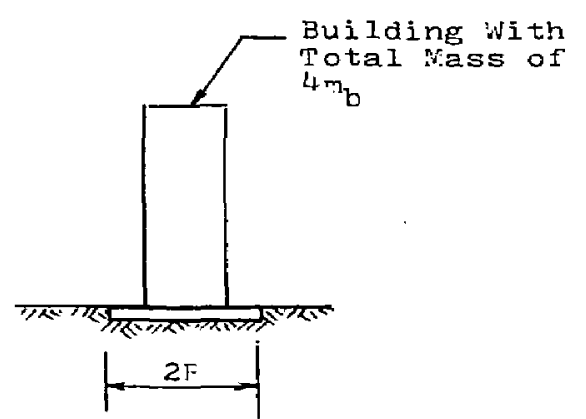

(b)

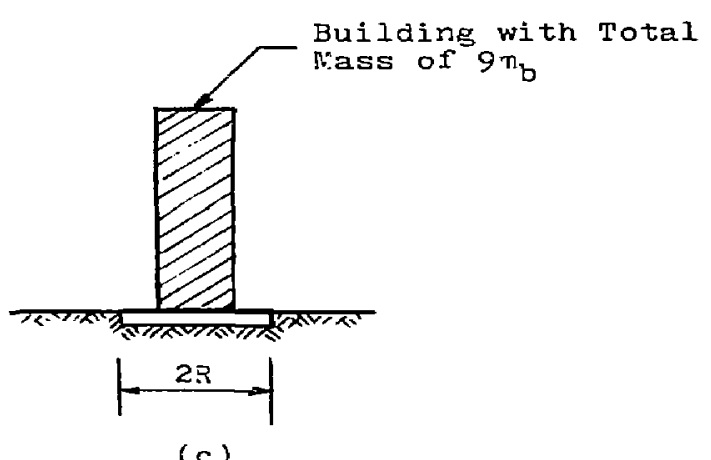

(c)

Fig. 3-1 Three Structures Founded on Identical Soil Fourdation Media. liaving Identical Base Dimension But Different Vass 


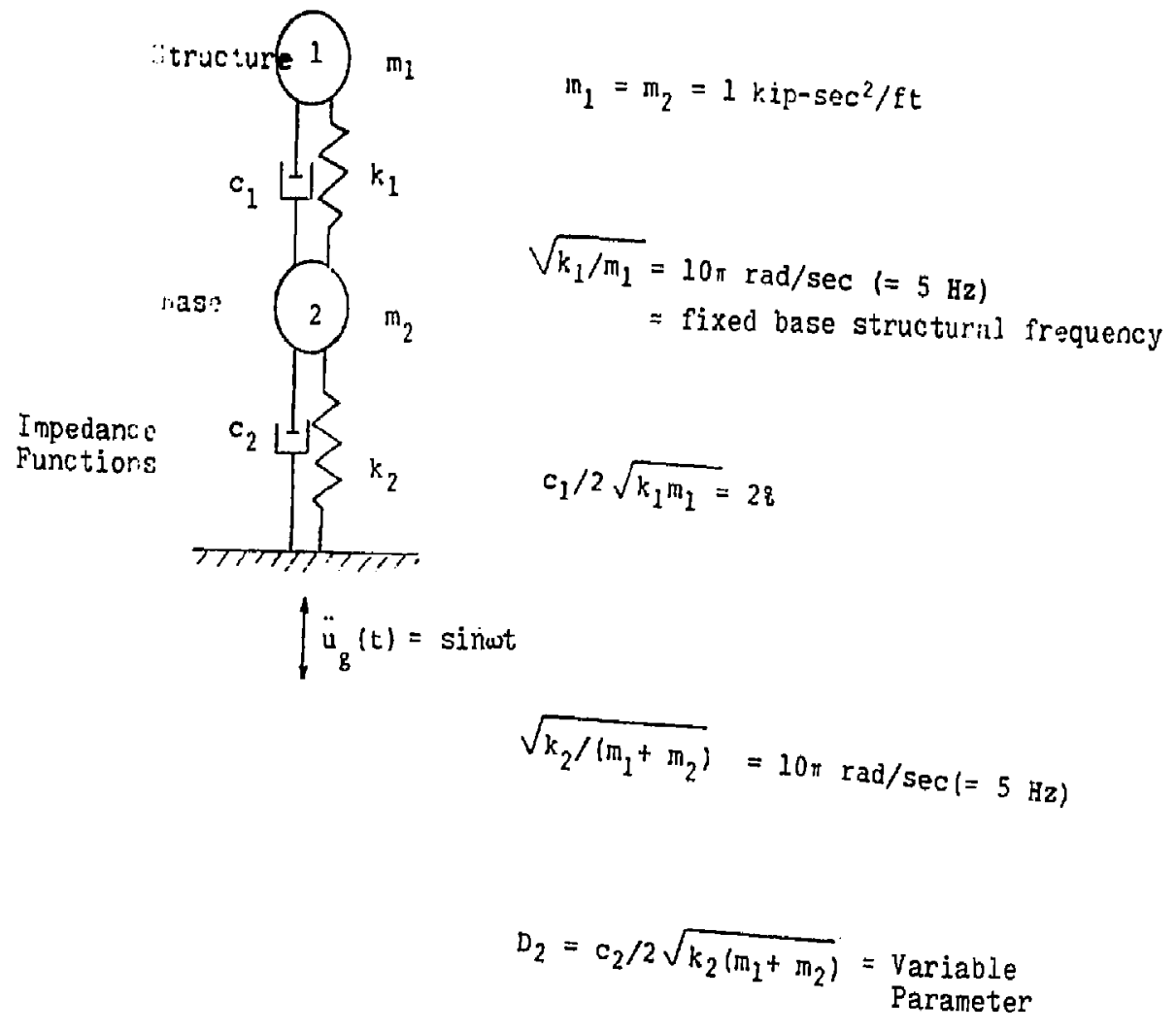

Frequencies of the 2-mass systiem :$$
\left\{\begin{array}{l}
\bar{w}_{1}=3.8 \mathrm{~Hz} \\
\bar{w}_{2}=9.2 \mathrm{~Hz}
\end{array}\right.
$$

Fig. 3-2 The one-liass itructure and Soil Interaction system for Vertical Vibrations 


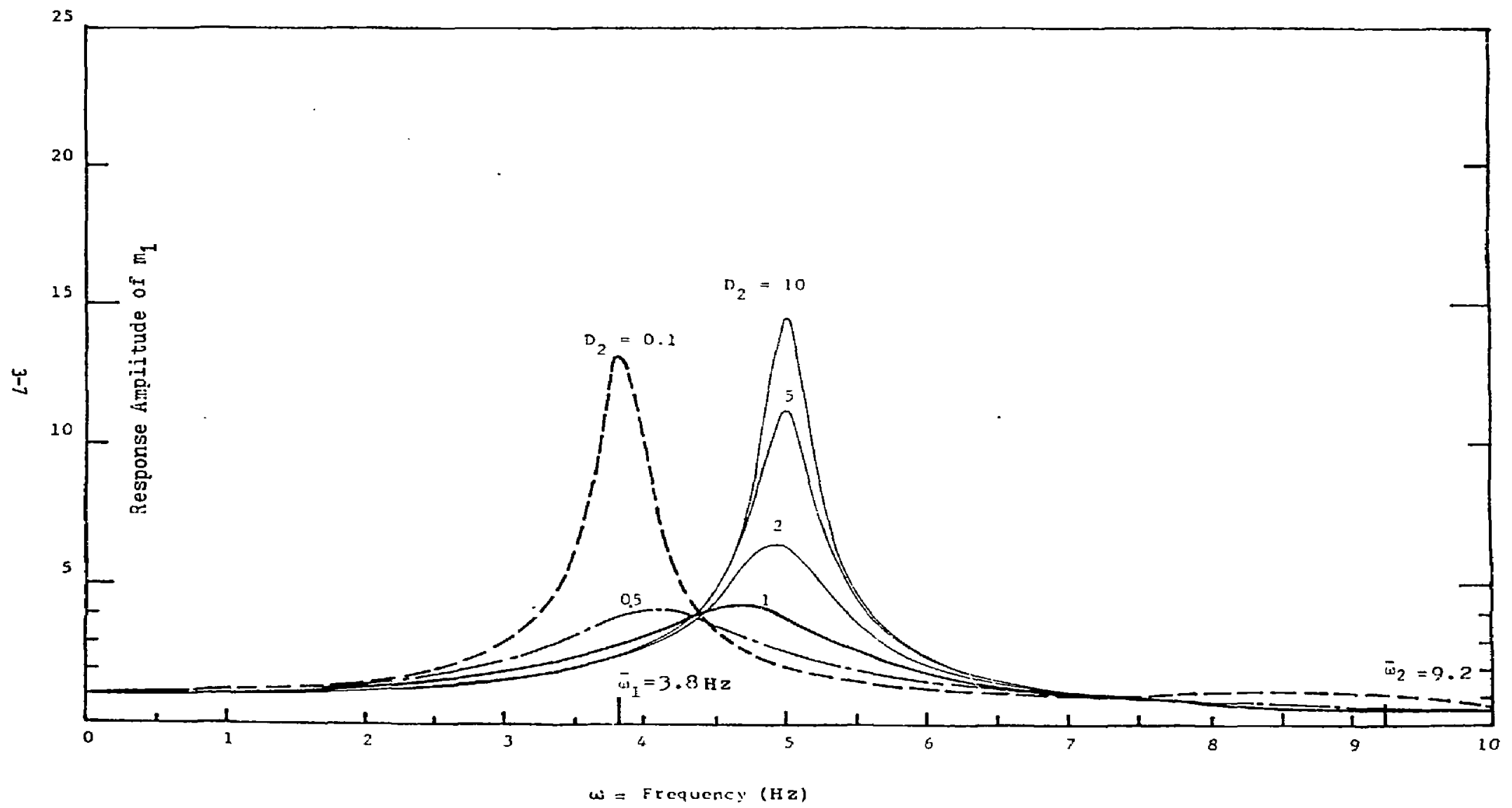

Fig. 3-3 Response Amplitude of $m_{1}$ As a Function of Excitation Frequency $\omega$ and $D_{2}$ 
In the impedance approach to soil-structure interaction analysis, the equations of motion should explicitly incorporate the impedance springs, $K$, and dampers, $C$, in the system stiffness and damping matrices, respectively. Moreover, when the damping property of the structure is specified in terms of the fixed-base structural modal damping, which is the current practice, a certain transformation of the coordinates must be applied to the equations of motion so that the structural modal frequences, $\omega_{j}$, and damping values, $\beta_{j}$, are explicit parameters in the transformed system stiffness and damping matrices, respectively (e.g., Ref. 13).

In general, because the impedance springs and dampers are frequency-dependent, the equations of motion are solved rigorously by the method of Fourier transformation in the frequency domain. When frequency-independent impedances can be used for uniform soil sites, for example, the rigorous solution can be obtained by the methods of Fourier transformation, complex modal analysis, or direct integration. The method of nornal mode superposition, though widely used in engineering practice, yields only approximate solutions because classical normal modes do not exist, in general, for the problen under consideration. Besides, under certain conditions the nomal mode approximation may be unacceptable--a very important point.

In conjunction with the application of modal superposition, controversies arise with regard to the technique for determining the composite modal damping, $\bar{\beta}_{k^{\prime}}$ and $i t s$ magnitude. It has often been postulated that the composite modal damping value should be limited in order to produce conservative structural response.

This section highights the limitations of modal superposition for soil-structure interaction analysis. A proper understanding of the role of the composite modal damping in such analyses is developed.

\subsection{LIMITATIONS}

The very nature of modal superposition dictates that the resonant frequencies of the structural response invariably coincide with the frequencies of the soil-structure system, $\bar{\omega}_{k} \cdot$ As illustrated previously in Fig. 3-3, the resonant frequencies of the system will gradually increase 
toward the rixed-base structural frequencies, $\omega_{j}$, as the radiation damping increases. Such a frequency shift cannot be done with nortal mode methods, no matter what composite darting values are used. To illustrate this point, consider again the two-mass systen in Fig. 3-2.

Figure 4-1 shows the normal mode solutions for the response amplitude of structural mass $m_{q}$ for several assumed composite modal damping ratios, $\bar{\beta}_{q}$ and $\bar{\beta}_{2}$. A close comparison of Fig. 4-1 and Fig. 3-3 reveals the following:

(a) When $D_{2}=0.1$ (damping ratio for the foundation), the normal mode approximation is acceptable, and the required values for composite modal damping are, by inspection, $\bar{\beta}_{1} \equiv 4 \%$ and $\bar{\beta}_{2} \equiv 40 \%$.

(b) When $D_{2}$ exceeds 0.5 , the normal mode approximation becomes less acceptable, regardless of the values of the composite nodal damping. In fact, when $\mathrm{D}_{2}$ exceeds 1.0, a fixed-base-structure assumption turns out to be a better approximation, provided that an effective structural modal damping greater than $2 \%$ is used. As $D_{2}$ increases further, the effective damping rapidly converges toward 2\%--the fixed-base structural damping specified initially.

In conclusion, modal analysis shouid be used with caution because its validity largely depends on the magnitude of the radiation damping and the structural rigidity relative to impedance springs. Provided that the relative structural rigidity is not too great, the modal superposition approximation is generally acceptable until the radiation damping, expressed in terms of the dimensionless ratio $D$, exceeds the range of 0.8 to 1.0 .

\subsection{COMPOSITE MODAL. DAMPING}

\subsubsection{Determination of Composite Hodal Damping}

When the impedance functions permit the normal mode approximation, the value of the composite modal damping also dictates how close are the amplitudes of the approximate and rigorous solutions. Several techniques are available for estirating modal damping values (e.g., Ref's. 13, 14, 15). These methods are not compared at great length here. Note, however, that a suitable technique must always correlate the approximate and rigorous solutions during 
the process of computing the composite modal damping (e.g., Ref. 13). Although the correlation criteria may vary from one person to another, the variation is usually small, and one can always foretell the quality of the approximation with respect to the rigorous solution. For instance, the best estimates for $\bar{\beta}_{1}$ and $\bar{\beta}_{2}$ for the two-mass system discussed in Sec, 1.1 (a) were based on correlating the approximate and rigorous solutions for the response of $m_{1}$.

On the other hand, any technique that computes the composite modal damping without a correlatior. with the rigorous solution will render the degree of approximation uncertain. This is the case with most existing techniques (e.g., Refs, 14, 15). Typically, these techniques compute the composite modal damping as a crtain weighted average of the structural damping $\beta_{j}$ and the radiation damp.ng ratios, $D_{x}$, and $D_{r}$. A convenience, and, hence, a defect, of these techniques is that tiey do not require formal formulation of the equations of motion. The nonuniqueness of the parameters, $D_{x}$ and $D_{r}$, adds additional uncertainty to the computed damping vajues. A general trend has been observed--these techniques usually overestimate the required modal damping and, hense, underestimate the structural response, particular': when the radiation damping ratios are much larger than the structural damping (Refs. 13, 14).

\subsubsection{The Proper Role 0: Composite Modal Damping}

To understand the role of the composite modal damping, it is imperative to first observe the following premise:

Given that the impedance functions are valid representations of the foundation, that the rigonous solution must be obtained by one of the three numerical analysis methods mentioned above, and that normal mode approximation is permissible, then the required composite modal damping values, regardless of their magnitudes, must be set in such a way that the optinum approximation for the structural response can be achieved.

Thus, to arbitrarily limit the computed values of the composite damping is, in reality, to render a poor approximate solution. Unnecessary conservatism will be introduced into the structural response, and sometimes extra floor spectrum peaks will be created with respect to the rigorous solution. For example, consider again the two-mass system. For the case of $D_{2}=0.1$, the best estimates for $\bar{\beta}_{k}$ are, according to Sec. 4.1 (a), $\bar{\beta}_{1} \equiv 4 \%$ and $\bar{\beta}_{2} \geq 40 \%$. 
Say $\bar{\beta}_{2}$ is to be reduced to $10 \%$. Then, the consequence is obvious: based on Fig. 4-1, an extra spectral peak having an appreciable amplitude could be created at $\bar{\omega}_{2}=9.2 \mathrm{~Hz}$ on the floor spectrum of $\mathrm{m}_{1}$.

In general, unless the radiation damping is small, at least two modes (one mode for vertical analyses) are inevitably associated with large values of composite modal damping. These are the modes for which substantial participation of the base translation and/or base rocking takes place, which is physically understandable. For a given problem, if such modes do not occur within the frequency range of interest, it does not maan that they do not exist. They are at higher frequencies.

\section{3 VASE STUEY}

Reference 16 presents a very imannating axso atudy of the structure-foundation interaction effect for a seven-story braced truss chime tower (Fig. 4-2). A frequency sweeping test was done with a shaker placed on the fourth floor. Apparent resonances were observed at about 2.4 to $2.5 \mathrm{~Hz}$ and at 7.9 to $8.5 \mathrm{~Hz}$, and the associated damping values were estimated to be about $2.5 \%$ and $5.5 \%$, respectively.

The authors then established a mathematical model for the structure and attempted an analytical correlation with the fiald test results. Two different approaches were used. In the first approach, the sojl-structure interaction effect was simply assumed to be negligible, and a fixed-base model was considered. The frequencies of tha first two modes of the fixed-base model are compared with the measured values in Fig. 4-3. The correlation is reasonably good, indicating that the interaction effect is indeed insignificant. As ne may anticipate, the analytical modal frequencies are siightly higher than the test results because the deformability of the foundation soil was reglected.

In the second approach, frequency-independent impedance springs, $K_{x}$ and $R_{r}$, were computed to represent the foundation. The frequencies and mode shapes of the first three modes are shown in Fig. 4-3. Note that the second mode $(4.7$ to $6.9 \mathrm{~Hz}$ ) was not observed in the field tests, nor in the fixed-base model. This by no means implies that the interaction model is inaccurate, because the first and third modes agree closely with the test results. The only logical interpretation is that the second mode must be highly damped. Such an inturpretation is supported by the fact that the 
second mode shape is predominantly translation and rocking of the base, and, hence, a high damping for that mode is anticipated. Though the authors did not attempt to compute the composite modal damping, they estimated that the second mode must have a umping of at leasi $50 \%$. 


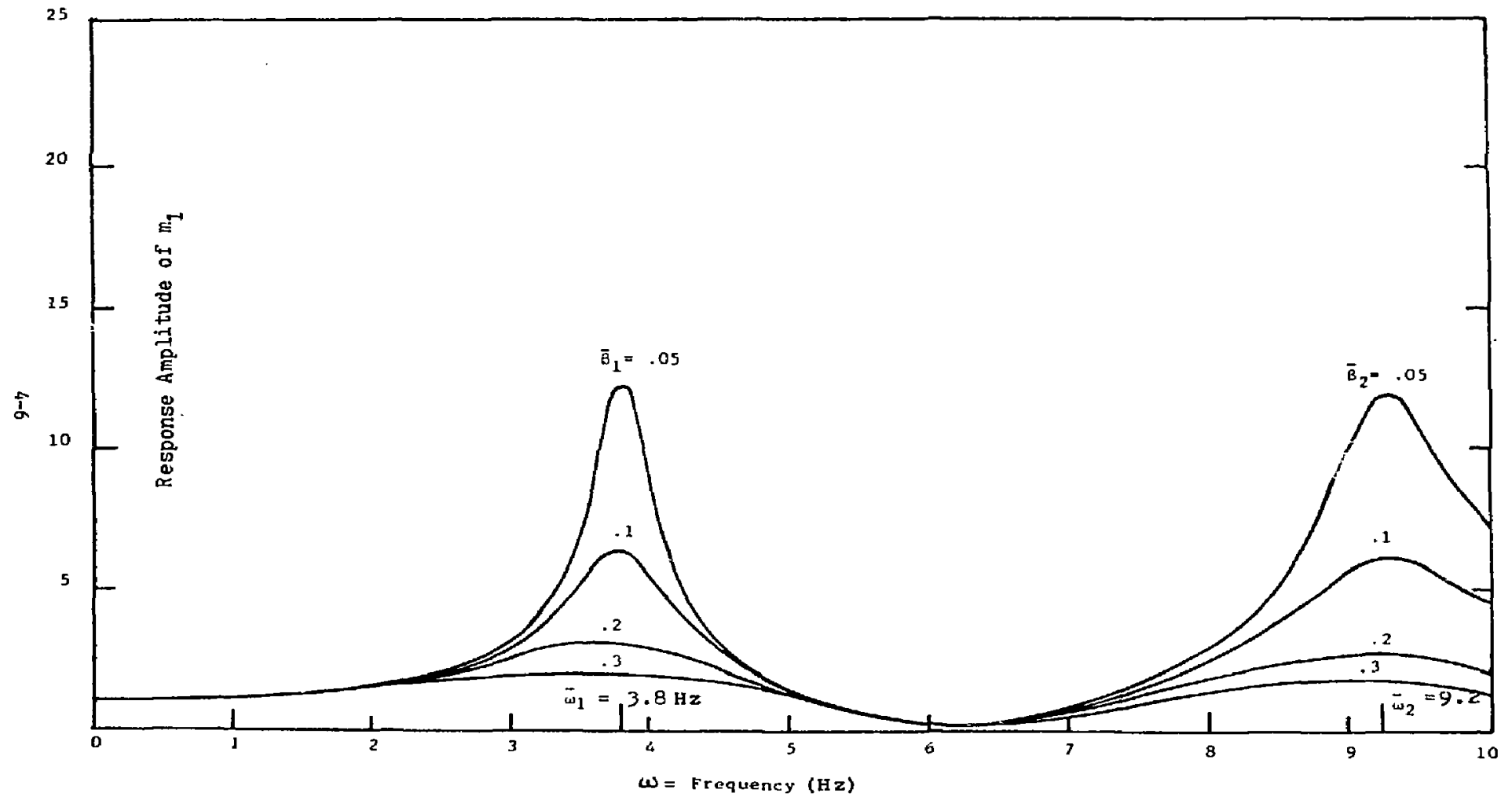

Fig. 4-1 Normal mode Approximation for Amplitude of $m_{1}$ As a Function of $\bar{\beta}_{1}$ and $\vec{\beta}_{2}$ 

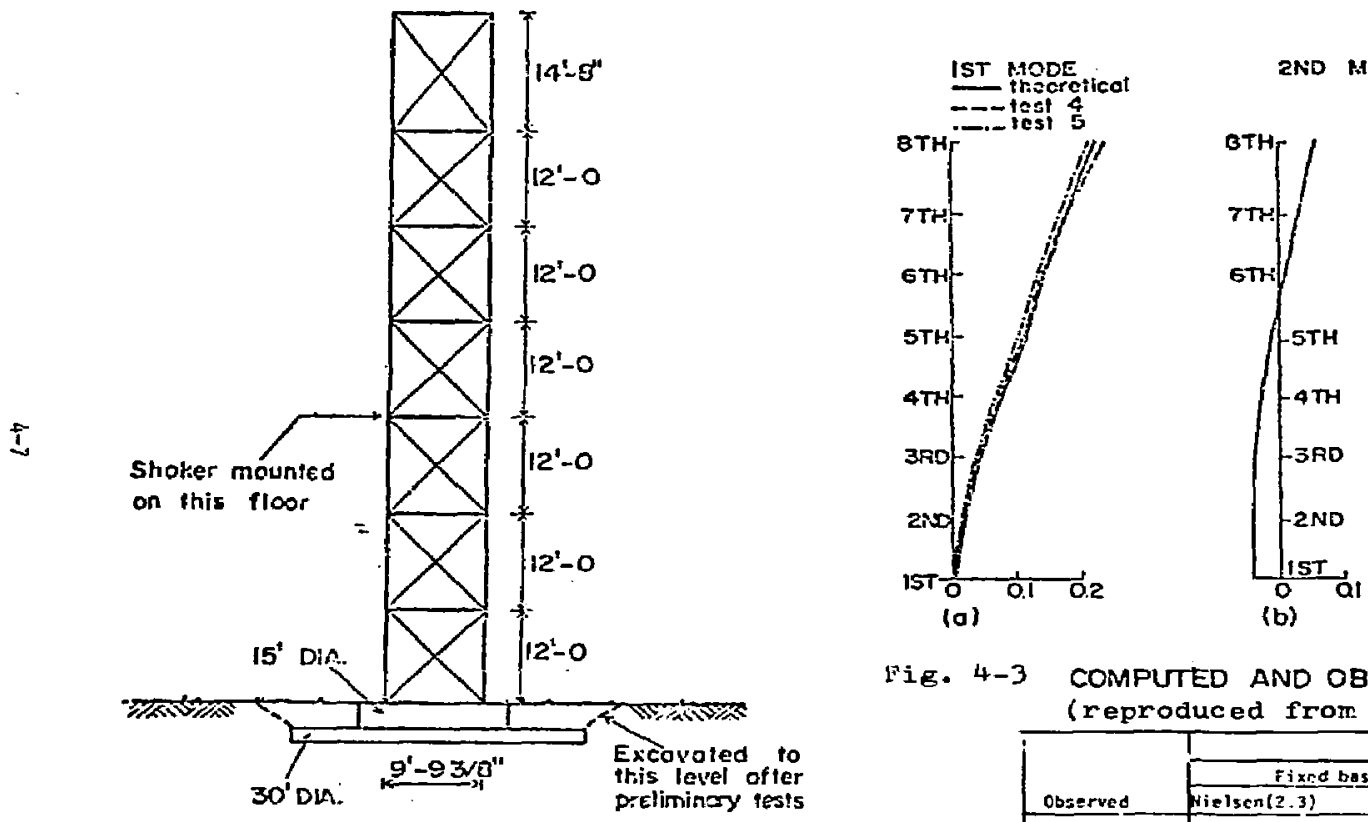

Thesticol

- - - test 3 iesst colum

II. 4-3 COMPUTED AND OBSERVED MODE SHAPES

\begin{tabular}{|c|c|c|c|}
\hline \multirow[b]{3}{*}{ Dbserved } & \multicolumn{3}{|c|}{ Colculated } \\
\hline & Fixe & & With interaction \\
\hline & $\operatorname{Ni}=1 \operatorname{sen}(2.3)$ & priters & Writers \\
\hline $2.4-2.5$ & $2 . \varepsilon$ & 2.30 & $2.41-2.44$ \\
\hline & & & $4.73-5.01$ \\
\hline
\end{tabular}

ELEVATION OF CHIAETES TOHER

(reproduced from Ref. 16) 


\section{EVALUATION OF FIELD TESTS}

In this section, information from several available dynamic field tests is reviewed to assess the validity of the impedance theory. Of particular interest is the evaluation of the analytical radiation damping values in Tables 2-1 and 2-2, which, though often used, are extremely controversial.

Some field tests were performed on structures, others on footings. It is important to differentiate the two. The damping ratio deduced from tests on structures is equivalent to the composite modal damping for the interaction system, $\vec{\beta}_{\mathrm{k}}$, while that from tests on rootings is equivalent to the defined damping ratio, $D$, which comprises the combined effects of radiation damping and soil material damping. Each available test result is reviewed separately below.

5.i CASE I-HAMAOKA NO. 1 BWR REACTOR BUILDING (Ref. 17)

5.1.1 Structural Data

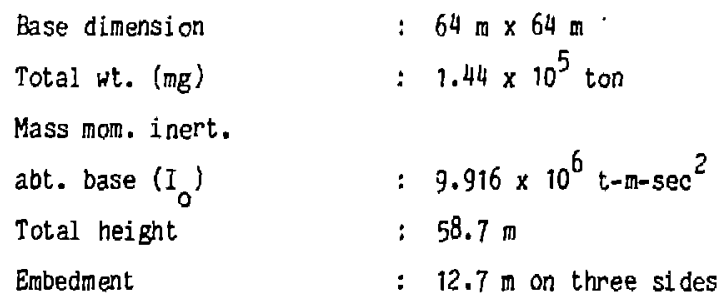

\subsubsection{Foundation Data}

$\begin{array}{ll}\text { Shear wave velocity }\left(V_{\mathrm{s}}\right) & : 800 \mathrm{~m} / \mathrm{sec} \text { on ave, } \\ \text { Shear modulus }(G) & : 1.312 \times 10^{5} \mathrm{t} / \mathrm{m}^{2} \\ \text { Unit weight }(\rho g) & : 2.01 \mathrm{t} / \mathrm{m}^{3} \\ \text { Poisson's ratio } & : 1 / 3\end{array}$


From Table 2-2, the equivalent radii for calculating the radiation damping are $R_{x}=36.2 \mathrm{~m}$ and $R_{r}=36.6 \mathrm{~m}$, and the following were computed:

$$
\begin{aligned}
& K_{x}=2.24 \times 10^{7} t / m \\
& D_{x}=513\left(D_{x}=C_{x} / 2 \sqrt{k_{x}}\right) \\
& K_{r}=2.58 \times 10^{10^{n}} t-m / r a d \\
& D_{r}=314\left(D_{r}=C_{r} / 2 \sqrt{R_{r} I_{0}}\right)
\end{aligned}
$$

The authors did a complete analytica. ediction of the composite modal damping, using the frequency-dependent in nce functions suggested by Tajimi (Ref. 18) for a uniform half space. Figure 5-1 compares the simplified, frequency-independent impedances with the frequency-dependent impedances. Note that for horizontal motions $K_{1}(\omega)$ is to be compared $w 1$ th $K_{x}$, and $K_{2}(\omega)$ with $\omega C_{x}$. Similarly, for rotational motions $K_{1}(\omega)$ is to be compared with $K_{r}$, and $K_{2}(\omega)$ with $\omega C_{r^{*}}$ of particular interest is the comparison of the radiation damping ratios. At the fundamental system frequency $\bar{\omega}_{1}$, which was analytically computed to be $2 \pi \times 5 \mathrm{~Hz}$ and $2 \pi \times 5.2$ $\mathrm{Hz}$ for the EW and NS directions, respectively, the effective EW radiation damping ratios for the frequency-dependent impedance are:

$$
\begin{aligned}
& D_{x}\left(\bar{\omega}_{1}=2 \pi \times 5 \mathrm{~Hz}\right)=60 \% \\
& D_{r}\left(\bar{\omega}_{1}=2 \pi \times 5 \mathrm{~Hz}\right)=28 \%
\end{aligned}
$$

As the frequency exceeds the fundamental mode frequency, the effective radiation damping ratio for the frequency-dependent impedance will al so increase, as suggested by Fig. 5-1,

\subsubsection{Frequency and Composite Modal Damping}

The authors established a mathematical model for the structure, and assumed that the structural modal damping $\beta_{j}$ is $2 \%$ for all modes. the interaction system was coupled with the frequency-dependent foundation impedances and analyzed by the method of complex modal analysis. This method produced the rigorous solutions for the system frequency and the composite 
modal damping. They are compared with the experinental values in the following table, for the first mode only.

$\mathrm{EW}$

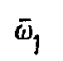

Theory

Experiment<smiles>[3H][3H]</smiles>

$17.7 \%$
NS<smiles>[3H][Te]</smiles>

$5.2 \mathrm{~Hz}$

19.84

22.5 to $28.3 \% *$

(Ave. $=24.6 \%)$
$5.0 \mathrm{~Hz}$

17.5 to $31.5 \% *$

(Ave, $=22.05$ )

*The experimental values vary from floor to floor.

\subsubsection{Summary}

Comparison of the analytical and experimental values for system frequency and composite damping for the first mode justlfies the adequacy of the impedance theory. Note that the experimental damping consists of the effects of soil material damping and embedment, while the analytical valua represents only the radiation damping from the elastic half-space theory.

From the comparisons of $D_{x}$ and $D_{r}$ between the frequency-dependent and frequency-independent impedances, it is reasonable to predict that similar analytical results would be obtained when the frequency-independent impedances are used in the calculations.

5.2 CASE II--HAMAOKA NOS. $1 \& 2$ BWR REACTOR BUILDINGS (Ref. 19)

Forced vibration tests, similar to those performed on Unit 1 in Case I were conducted on Unit ? after it was built. More data were collected, but the results are essetially the same as those obtained for Case I. Thus, the autiors did not attempt another analytical correlation with the test results. The following points are worth mentioning:

- Through-soil structure-structure interaction appeared to be insignificant, when the data are compared between Ref. 17 and 19 .

- By using a regression analysis technique, the authors were able to more precisely identify the various modes, whether highly damped or not. Based on this technique, the modal damping values for the different frequency ranges are as follows:
1 to $4 \mathrm{~Hz}$
...... 40 to $50 \%$ (essentially ground movements)
4 to $5.7 \mathrm{~Hz}$
$20 \%$
5.7 to $9 \mathrm{~Hz}$
...... 3 to $15 \%$ 
- Because of the similar experimental results in Cases I and II, Case II provides additional verification of the adequacy of the radiation damping theory.

5.3 CASE III--NUCLEAR SAFETY RESEARCH REACTOR BUILDING (REP. 20)

\subsubsection{Structural Data}

$\begin{array}{ll}\text { Base dimension } & : 21 \text { m diam (circular) } \\ \text { Total wt. (mB) } & : 7585 \text { ton }\end{array}$

Vt. mom. inert.

abt. base $\left(I_{0} g\right) \quad: 1.01 \times 10^{6} \mathrm{t}-\mathrm{m}^{2}$

Height $\quad: 30 \mathrm{~m}$

Embedment $\quad: 10 \mathrm{~m}$

5.3.2 Foundation Data (Layered Soil Site)

$\begin{array}{ll}\text { Shear wave velocity } & : 400 \mathrm{~m} / \mathrm{sec}, \text { ave. } \\ \text { Shear modulus } & : 3.27 \times 10^{4} \mathrm{t} / \mathrm{m}^{2} \text { ave. } \\ \text { Unit weight } & : 2.0 \mathrm{t} / \mathrm{m}^{3} \text { ave. } \\ \text { Poisson's ratio } & : 0.45 \text { ave. }\end{array}$

\subsubsection{Impedances}

The following values were obtained based on Table 2-1:

$$
\begin{array}{ll}
K_{x}=1.777 \times 10^{6} \mathrm{t} / \mathrm{m} & K_{r}=1.84 \times 10^{8} \mathrm{t}-\mathrm{m} / \mathrm{rad} \\
D_{x}=369 & D_{r}=9.24
\end{array}
$$

\subsubsection{Experinental Results}

Resonance was observed at 5 and $6 \mathrm{~Hz}$ in one horizontal direction and at 5 $\mathrm{Hz}$ in the other horizontal direction. The associated damping values were found to be about $15 \%$ and $18 \%$, respectively. 


\subsubsection{Surmary}

The experimental value of the composite modal damping is smaller than that in Case I. The analytical values for $D_{x}$ and $D_{r}$, the impedance damping ratios, are also smaller than those in Case I. Thus, reasonable agreement between the experimental and analytical composite modal damping values can be anticipated although the latter was not available from Ref. 20.

\subsection{CASE IV--CONCRETE SLAB FIELD TESTS AT SONGS $2 \& 3$ SITES (Ref, 21)}

To gather realistic soil-structure interaction analysis parameters for the design of Units 2 and 3 of the San Onofre Nuclear Cenerating Station (SONGS), vibration tests were performed on concrete slabs bullt at the construction laydown area of the Unit I site. Five types of concrete slabs representing different size, embedment condition, and geometry were built (Fig. 5-2). The configuration of the bottom of Slab No. 3 was built to sinulate the base slab configuration of a typical PWR containdent structure. Additional variations in embedment conditions for Slab Nos. 2 anr 3 were considered (Fig. 5-3).

Transient-l oad vibration tests were conducted. Figure 5-4 shows the mechanism (pull-release) for triggering the slab vibrations. The resultant slab accelerations ranged from 0.2 to $1.0 \mathrm{~g}$, conparable to the anticipated design ground accelerations at the site. The resonant frequency of the slab vibration ranged from 17 to $90 \mathrm{~Hz}$. As expected, the slab motions were typically damped sinusoidal motions.

The near-surface soil is the San Mateo Formation Sand. The shear wave velocity is about 800 to $1200 \mathrm{ft} / \mathrm{sec}$ for the top $15 \mathrm{ft}$ of soil, and the averaged value is about $930 \mathrm{ft} / \mathrm{sec}$.

The tests showed essentially the same resonant frequency for both the "horizontal" and roaking modes. Inspection of Figs. 5-2 and 5-4 shows why: for all the horizontal pull tests, the pulling load did not pass through the center of resistance, and significant rocking motion always occurred even though the tests were intended to produce only horizontal-mode slab motions. The slab motion traces shown in Fig. 5-5 for Slab No. 1 clearly confirm this observation.

Appendix A of Ref. 21 describes the details of the slab tests and the resonant frequencies from the various tests. Correlation between the field test results and Table 2-1 impedances is discussed below. 


\subsubsection{Impedance Springs}

When the mass of the slab is known, the effective soil spring constant can be calculated from the observed resonant frequency of the slab. The embedment appeared to have significantly increased the resonant frequency and, hence, the actual soil spring constant.

In general, with shallow or no embedment, the tests suggest that the impedance springs $k_{x}$ and $K_{v}$ given in Table 2-1 are sufficient. For the rocking mode, $k_{r}$ from Table 2-1 appears to overestimate the experimental value. From the analytical point of view, this is also anticipated because, as 11 lustrated In Fig. 5-1, the frequency-dependent impedance spring for the rotational mode is smaller than the $k_{r}$ from Table 2-1 for the frequency range under consideration. When applied to soil-structure interaction analysis, however, the frequency-independent approximation is still acceptable, as was justified in Ref. 7 for a uniform soil site. Moreover, from the practical point of vien, base slabs of the actual structures are all embedded to a certain extent and are seidom purely unembedded. According to the test results, any nominal embedment of the structural base will easily increase the field value of $K_{r}$ to surpass the analytical value from Tables 2-1 or 2-2.

\subsubsection{Impedance Damping}

The decay rate of the slab motion provides the value of the equivalent damping ratio, D. Note that the field value includes the combined effects of soil material damping and radiation damping. Comparison of the field and analytical values given by Tables 2-1 or 2-2, which accounts for only the radiation damping, is summarized in Table 5-1.

\subsubsection{Slab Nos. 1,2,4 and 5}

For the rotational mode, the analytical radiation damping adequately accounts for the experimental damping. Embedment appears to significantly increase the radiation damping, which is consistent with analytical predictions.

For the horizontal mode, the analytical radiation damping exceeds the experinental value by about 10 to $20 \%$. This is not surprising because, as 
mentioned above, the horizontal mode tests produced very strong coupling between the horizontal and rocking motions. Hence, the observed horizontal mode darping was lower than that anticipated on the basis of exciting a pure horizontal mode because the observed damping value represents a certain average of the rocking mode damping and the would-be horizontal mode famping.

For the vertical mode of slab motion, the test results suggest that the effective damping depends strongly on the stress distribution of the soil beneath the slab and on the amplitude of the motion. Note that, in reality, soils do not possess iension capability. During vertical vibrations of substantial amplitude, the bottom of the slab could partially separate from the soil, and the damping would be smaller than that from a low-amplitude vibration. Therefore, it appears reasonable to reduce the analytical radiation damping based on the acceleration of the slab motion.

\subsubsection{Slab No. 3}

This is a peculiar case because the comparison shows the analytical damping value grossly overestimates the field value for all three modes of slab vibration. A correlation between the theory and the field tests appears improbable. Intuitively, one would expect the contrary to occur because the annular ring and block at the bottom of the slab would produce a better "bond" with the soil than would a plat slab bottom.

Because Slab No. 3 was intended to simulate the actual configuration of a typical PWR containment base construction, it is imperative that more test studies be conducted to better understand the effect of the slab bottom configuration on impedance damping.

\subsection{CASE V--HARMDNC VIBRATION TESTS ON A STEEL BODY (Ref, 22)}

Reference 22 describes harmonic vibration tests conducted on a cubic steel body $(1 \times 1 \times 1 \mathrm{~m})$ that was subjected to different embedment conditions. Figures 5-6 and 5-7 illustrate the test configurations as well as typical footing response vs test frequency curves for the lateral and vertical vibration tests, respectively. Impedance damping for the unembedded case is evaluated here. For the embedded cases, it is apparent that the impedance damping increases with the ratio of embedment of the footing. 


\subsubsection{LATEFAL TEST}

In view of the manner in which the lateral vibrarion force was applied, the footing response would be primarily a rocking motion rather than the pure lateral translation o the unembedded case. Therefore, the test value of the damping can be correlated with the analytical rocking mode radiation damping, $D_{r^{*}}$ The damping value from the test is about $4 \%$ of critical for the unembedded case. For the analytical value, the following data are used in the calculation:

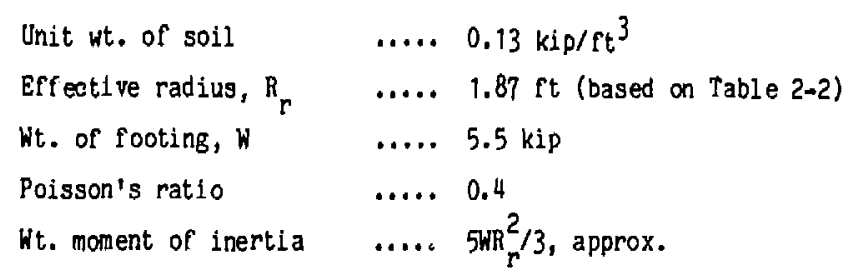

sccording to Table $2-1$, the rocking-mode radiation damping ratio is $D_{r}=2.8 \%$, which is comparable to the experimental value of $4 \%$.

\subsubsection{VERTICAL TEST}

The damping from the footing test for the unembedded condition is about 12\%. The analytical value, according to Table $2-2$, is found to be $35 \%$. Such comparison with the experimental walue is similar to that observed in the slab tests in Case IV.

The acceleration of the footing at resonance can be estimated to be about $0.65 \mathrm{~g}$. At such high acceleration, the footing-soil contact condition could substantially differ from that at low acceleration, which would account for the discrepancy between the analytical and the experimental damping values. 
TABLE 5-1. Comparison of equivalent darping ratios from analysis and testing.

\begin{tabular}{|c|c|c|c|c|}
\hline \multirow[b]{2}{*}{ Slab no. } & \multirow[b]{2}{*}{ Data source } & \multicolumn{3}{|c|}{ Damping ratio } \\
\hline & & $D_{V}$ & $\mathrm{D}_{\mathrm{x}}$ & $D_{r}$ \\
\hline $1 \& 2$ & $\begin{array}{l}\mathrm{A}^{\mathrm{a}} \\
\mathrm{F}^{\mathrm{b}}\end{array}$ & $\begin{array}{l}53 \% \\
29 \text { to } 60 \% \\
\text { (8 tests) } \\
\text { Ave. }=45 \%\end{array}$ & $\begin{array}{l}32 \% \\
17 \text { to } 44 \% \\
\text { (13 tests) } \\
\text { Ave. = } 26 \%\end{array}$ & $\begin{array}{l}13 \% \\
6 \text { to } 20 \% \\
\text { (14 tests) } \\
\text { Ave. = } 14 \%\end{array}$ \\
\hline & $F_{\text {ave }} / \mathrm{A}$ & 0.85 & 0.81 & 1.08 \\
\hline 3 & $\begin{array}{l}A \\
F\end{array}$ & $\begin{array}{l}\quad 66 \% \\
29 \text { to } 38 \% \\
(5 \text { tests) } \\
\text { Ave. }=33 \%\end{array}$ & $\begin{array}{l}\quad 41 \% \\
17 \text { to } 318 \\
(7 \text { tests) } \\
\text { Ave. }=25 \%\end{array}$ & $\begin{array}{l}29 \% \\
12 \text { to } 30 \% \\
\text { (6 tests) } \\
\text { Ave. }=20 \%\end{array}$ \\
\hline & $\mathrm{F}_{\text {ave }} / \mathrm{A}$ & 0.50 & 0.60 & 0.69 \\
\hline $4 \& 5$ & $\begin{array}{l}\mathrm{A} \\
\mathrm{F} \\
\mathrm{E}_{\text {ave, }} / \mathrm{A}\end{array}$ & $\begin{array}{c}53 \% \\
32 \text { to } 50 \% \\
0.75\end{array}$ & $\begin{array}{l}32 \% \\
18 \text { to } 40 \% \\
0.91\end{array}$ & 10 to $29 \%$ \\
\hline
\end{tabular}

$a_{A}=$ Analytical value based on Table $2-1$ or $2+2$.

$b_{F}=$ Field-test value. 


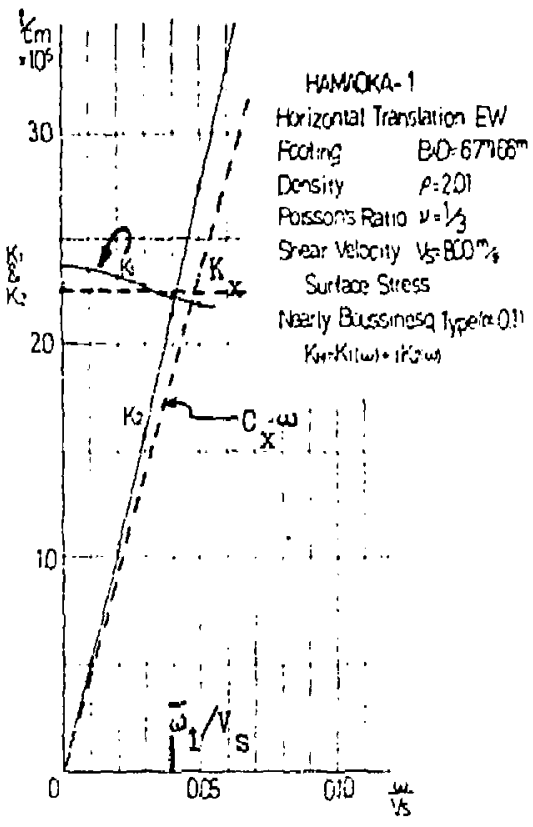

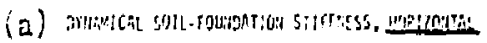

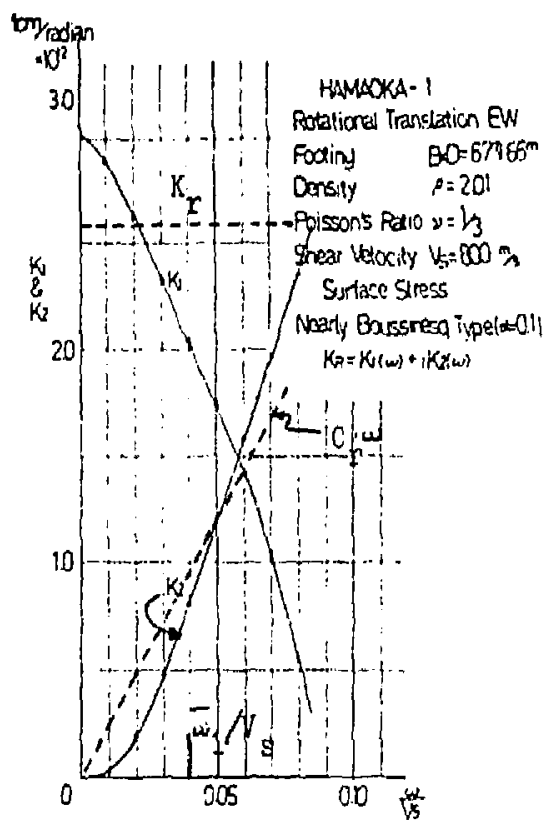

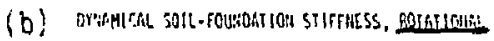

Fig. 5-i Jomparison Between Frequency-Independent Impedances From Table 2-2 And Frequency-Dependent Impedances From Ref. 17 


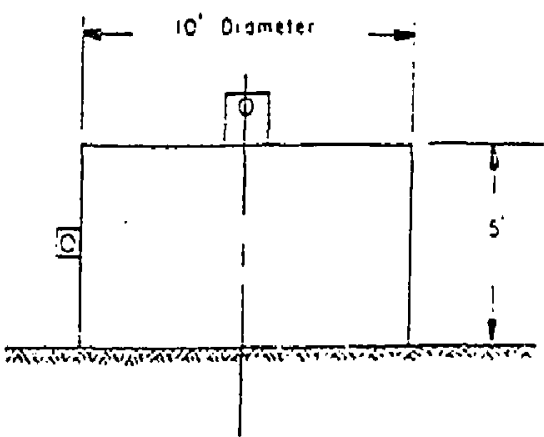

SLABND
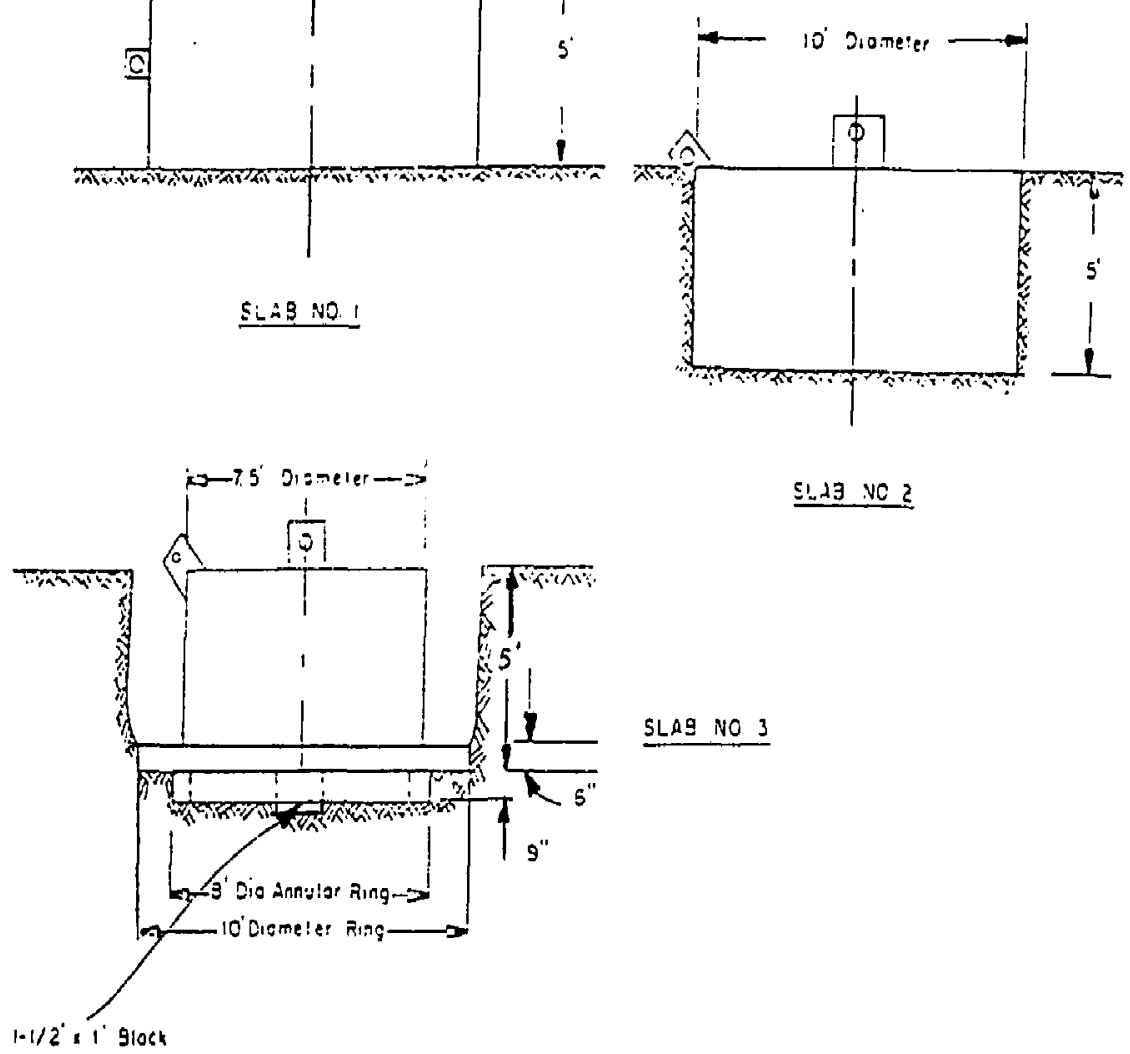

s.-29 vo?

SLAg No 3

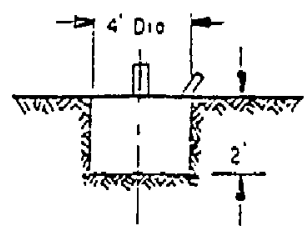

$\underline{S L A B}$ YCS

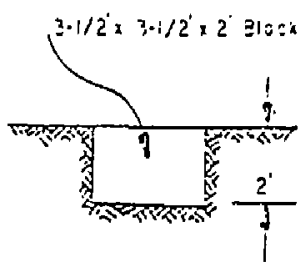

SLA2 SO 5

Fig. 5-2 The Five Types of Concrete Slabs in Case IV 


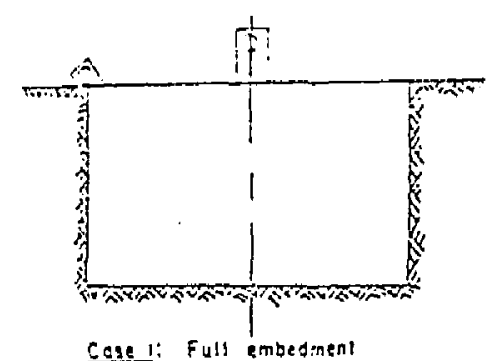

SLAE NO

Case 1: Fuls embedinent in nctural ground

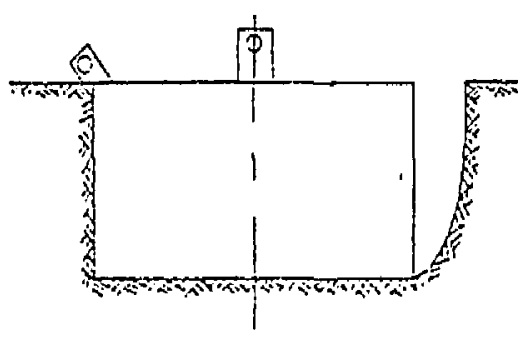

Case 2: Holl emsetemens

18. noturgl giound
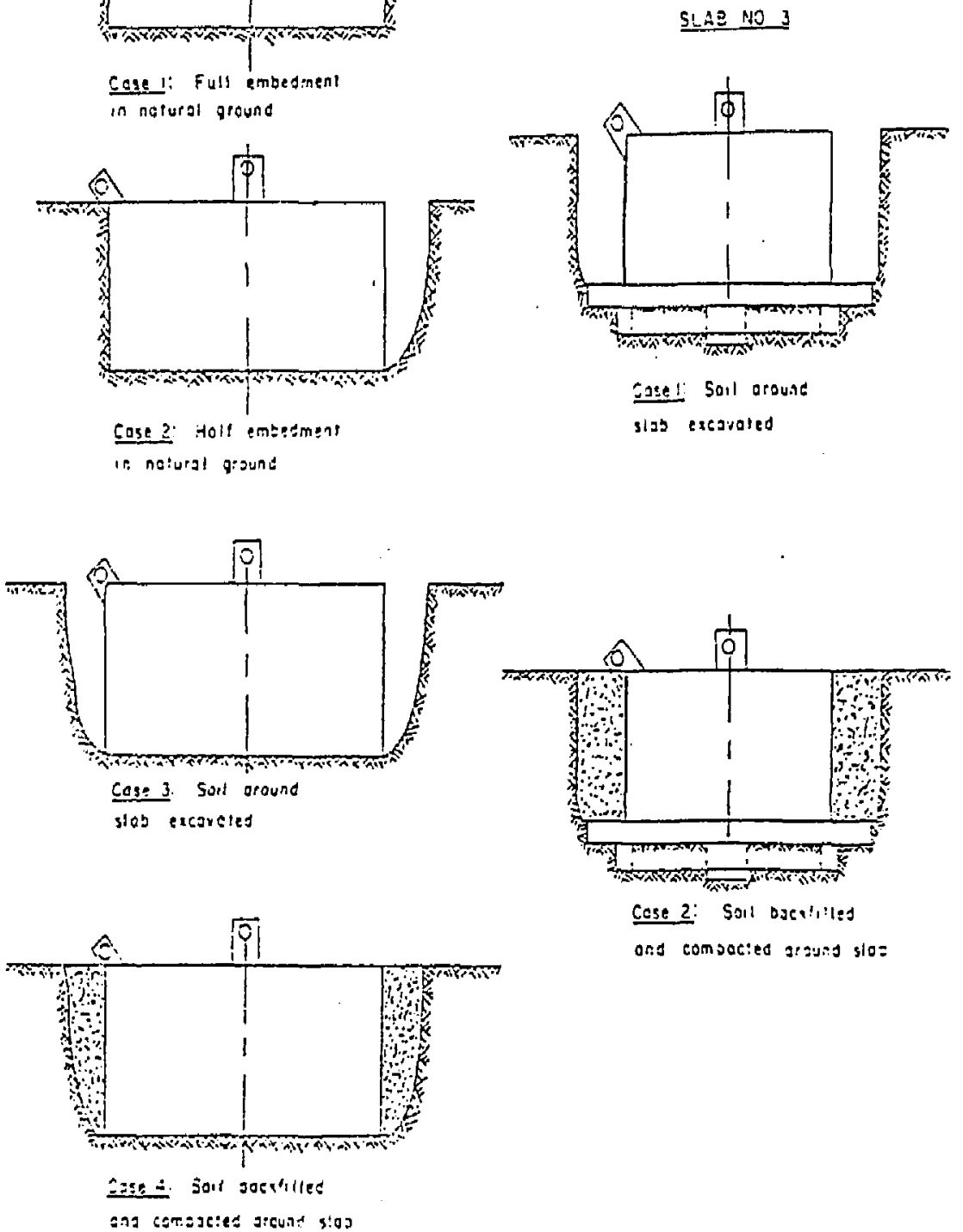

Fig. 5-3 Variation in Embedment Condition for Slab No, 2 and 3 (Reproduced from: Kef. 21) 


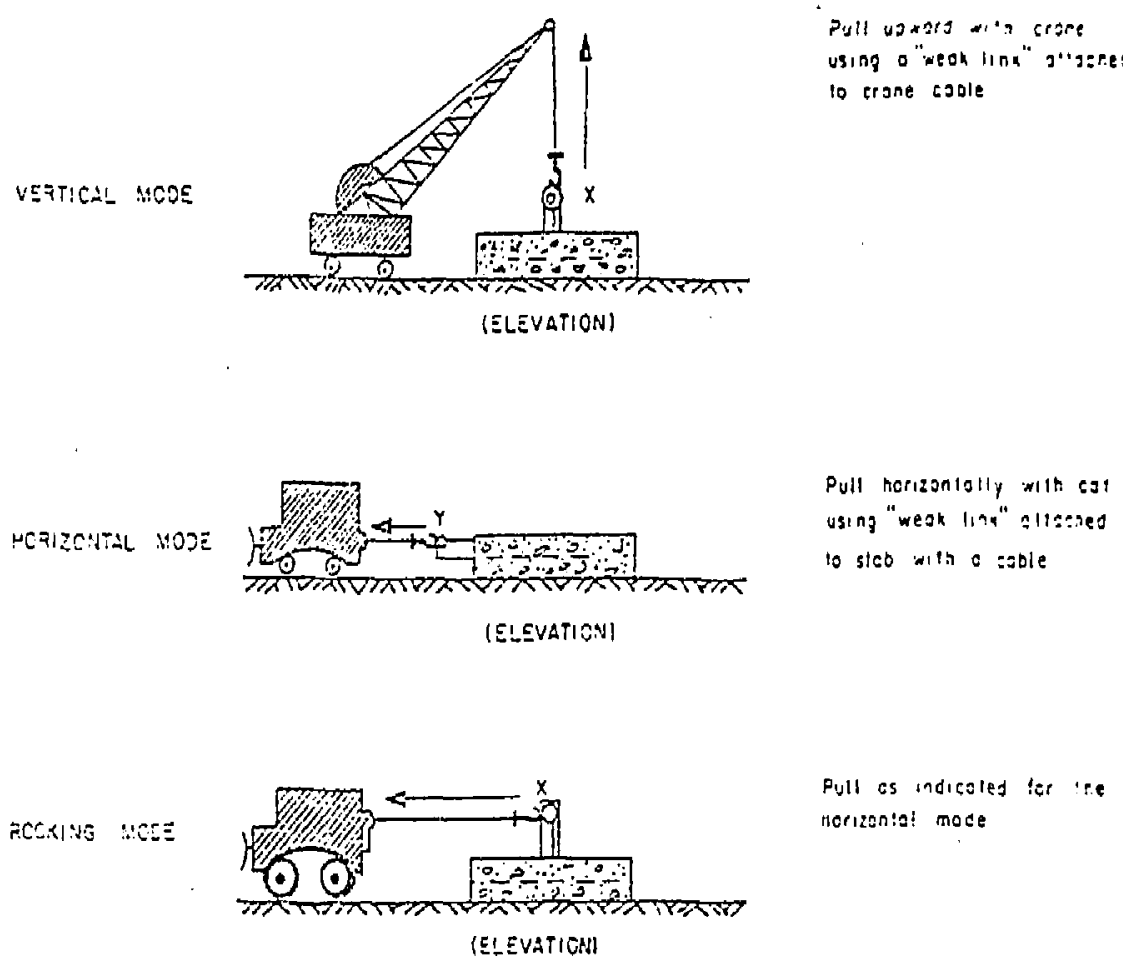

Fig. 5-4 lechanisr for Producing Transient Vibration of the Concrete Slabs (Feproduced from Fef. 21) 


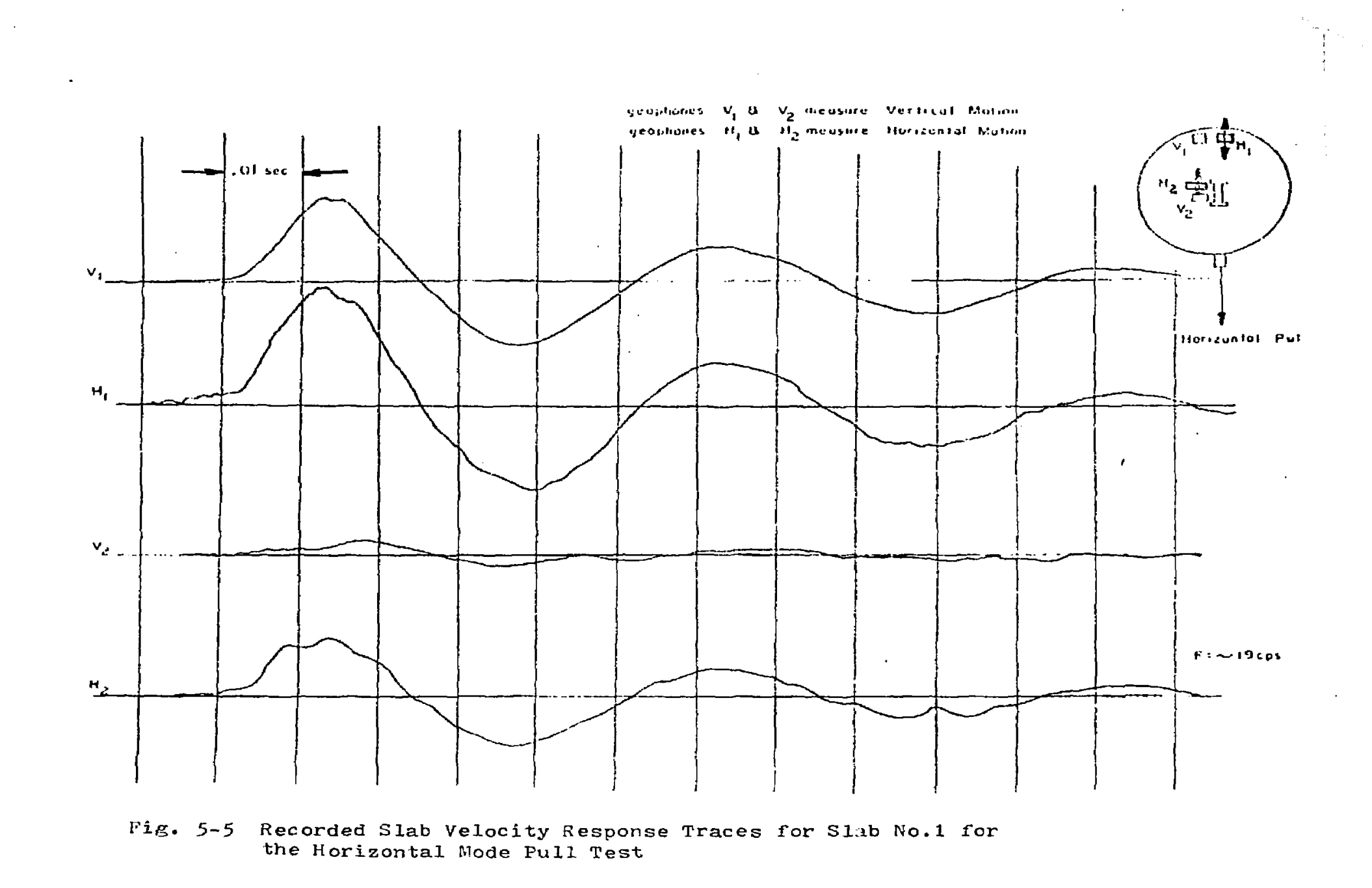




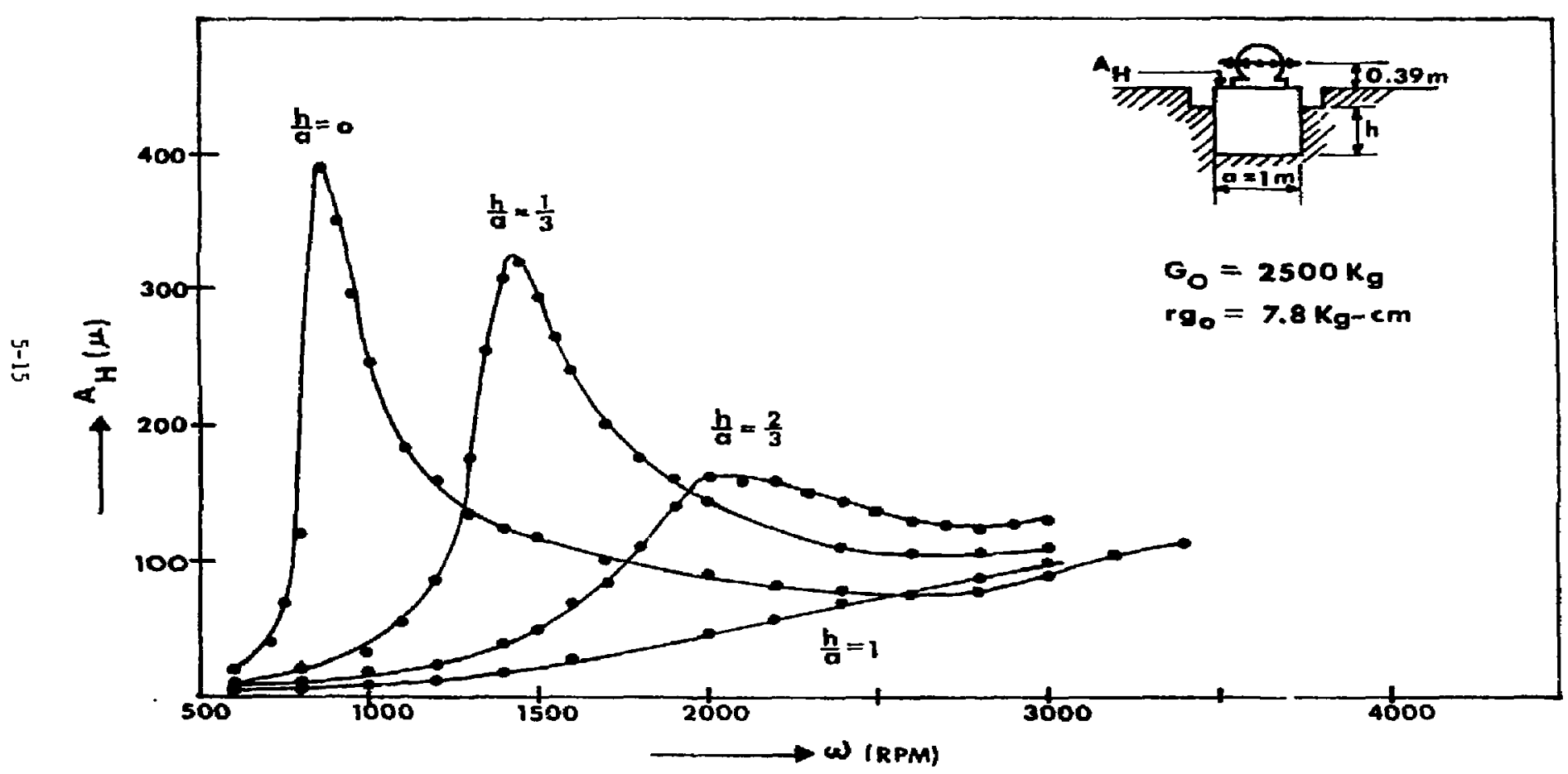

HORIZONTAL VIBRATION RESONANCE CURVES FOR DIFFERENT DEPTHS OF EMBEDMENT, AT SAME MAGNITUDE OF EXISTING FORCES (AFTER NOVAK, 1970)

irig. $5-6$ 


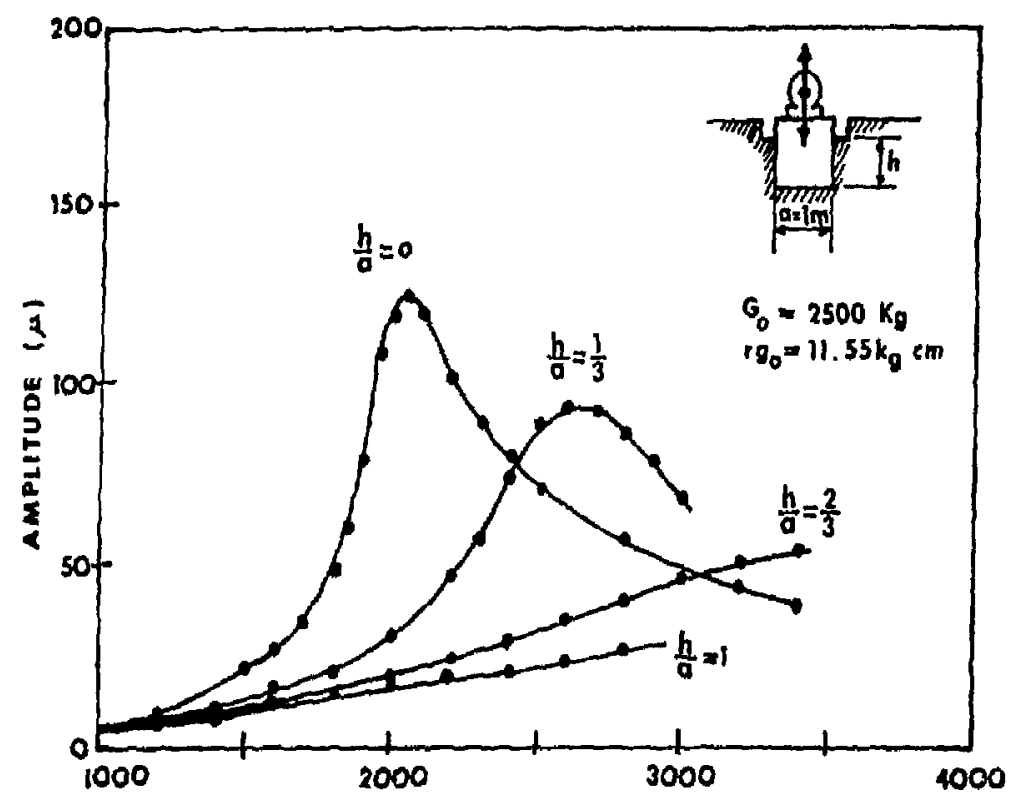

(a)UNDISTURBED SOIl aT SAME MAGNITUDE OF

EXCITING FORCES (AFTER NOVAK, 1970)

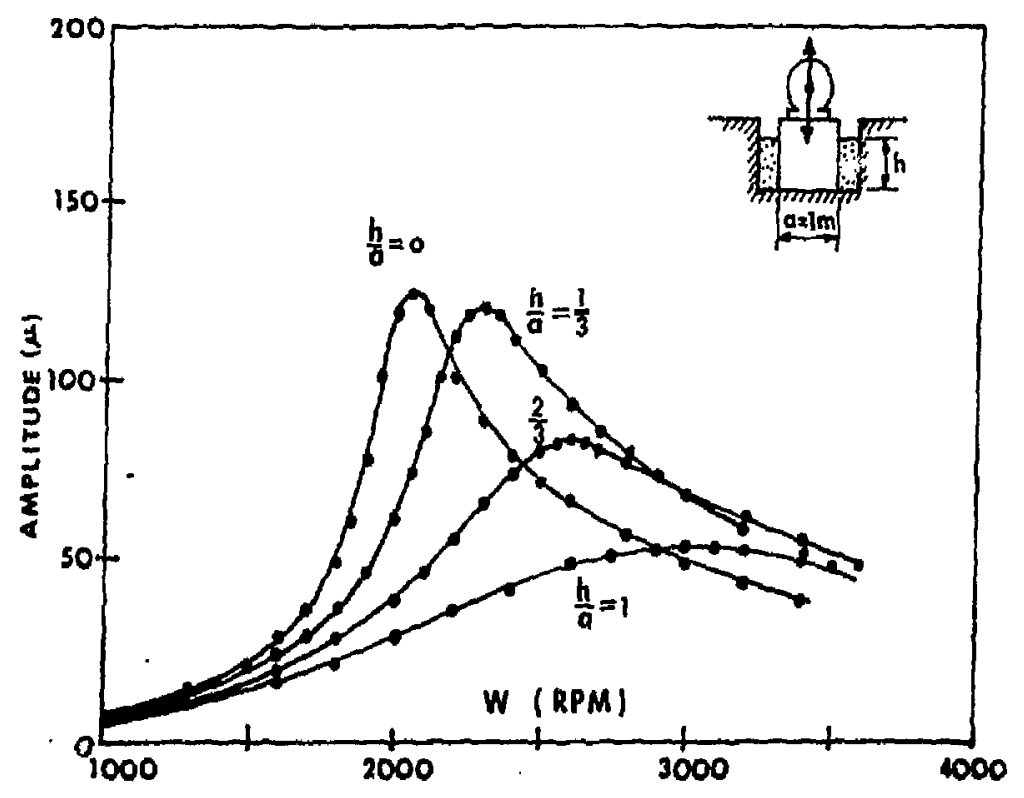

(b) COMPACTED FILL MATERIAL, at sAME MAGNITUdE OF EXCITING FORCES (AFTER NOVAK, 1970)

Fig. 5-7 Vertical Harmonic Vibration Test of Steel footing 


\section{SLMMARY AND CNQZUSIONS}

The analytical background and the basic assumptions $\mathbb{I}$ or the impedance theory were briefly reviewed. The role of radiation damping in soil-structure interaction analysis was discussed. The validity of nodeling the soil-structure interaction by using the frequency-independent impedance functions was evaluated based on data from several field-test cases. Finally, the proper procedure for performing soil-structure interaction analyses was discussed with emphasis on the modal superposition method. The limitations of this method were mentioned, and the proper technique for determinting composite modal damping was discussed.

The important conclusions and highlights of the discussions are listed bel OH.

\subsection{VALIDITY OF THE FREQUENCY-INDEPENDENT IMPEDANCE APPROACH}

- For the purpose of analysis, the assurption that the impedance functions are frequency-independent is acceptable for modeling the foundation at sites having fairly uniform soil profiles, but not necessarily for significantly layered sites.

- The impedance springs appear to be adequate representations in accordance with the field tests, and structural embedment effects appear to significantly increase the magnitude of the spring stiffness.

- For the horizontal and rocking modes of a base, the field tests suggest that analytical radiation damping alone is sufficient to represent the combined effects of soil material damping and actual radiation damping in the field. The only exception appears to be Slab No, 3 in Case IV, for which the analytical radiation damping overestimated the observed value. More tests on slabs of similar configuration are recommended.

- According to the field tests, the impedance damping appears to be sensitive to the amplitude of the base vibration for the vertical mode of base vibration, probably because the theory assumes tension capability for the soil in the derivation of impedance. The analytical radiation damping for vertical vibration, therefore, appears to have 
overestimated that cbserved in field tests and should probably be scaled down in proportion to the anticipate striciural base acceleration in actual applications. Based on the limited information from Cases IV and $V$, ihe scale factor may be on the order of $1-a_{B}$, where $a_{B}$ is the ground acceleration expressed in units of $\mathrm{g}$.

\subsection{THE EFFECT OF RADIATION DAMPING ON STRUCTURAL RESPONSE}

It was pointed out and demonstrated by examples thit the magnitude of the structural response is by no means inversely proportional to the magnitude of the conventionally defined radiation damping ratio, D. Consequently, arbitrarily reducing the radiation damping does not warrant a more conservative structural response. Moreover, floor spectra with erroneous pea!s frequencies could result from such arbitrary reductions.

\subsection{ANALYSIS PROCEDURE}

The following comments apply to analysis by modal superposition (the normal mode method):

- When frequency-independent impedance functions are used to model the foundation, the normal mode method produces only approximate solutions; the acceptability of such solutions depends largely on the magnitude of the radiation damping. To obtain it. rigorous solutions, one can use the methods of Fourier transf ormation, complex modal analysis, or direct integration.

- When the nomal mode method is acceptable, it is important to use the appropriate technique for determining the composite modal damping in order to produce the best approximate solutions. Most existing techniques tend to overestimate the composite modal damping and result in unconservative structural response.

- Given that the normal mode method is acceptable for a problem, and given that an appropriate technique is used to estimate the composite modal damping, the modal damping so determined need not be reduced. Any 
drastic reduction in the damping for highly damped modes will only

result in extra peaks in the floor spectra-man important point that has

been illustrated both analytically and experimentally. 
1. Lysmer, J. and Kuhlemeyer, K. L., "Finite Element Model for Infinite Media," Jour. Eng. Mech. Div., ASCE, Vol. 95, No. EM4, Aug. 1969, pp. 859-877.

2. Kausel, E., Roesset, J. M., and Wass, G., "Dynamic Analysis of Footings on Layered Media," Jour. Eng. Mech. Div., ASCE, Vol. 101, No. EM5, Oct. 1975, pp. 679-693.

3. Tseng, W. S. and Tsai, N. C., "Soil-Structure Interaction for, Transient Loads Due to Safety Relief Valve Discharge," 4th Int. Conf. Struct. Mech. in Reactor Tech., San Francisco, Calif., Aug.' 15-19, 1977.

4. Lysmer, J., Udaka, T., Seed, H. B., and Hwang, R., Complex Response Analysis of Soil-structure Systems by the Finite Elentent Method, EERC Report, Univ. of Calif, at Berkeley, 1974.

5. Tsai, N. C., Influence of Local Geology on Earthquake Ground Motions, Ph.D. Thesis Dissertation, Caltech, Pasadena, Calif., June 1969.

6. Schnabel, P. B., Lysmer, J., and Seed, H. B., "Earthquake Response Analysis of Horizontally Layered Sites, EERC Report, Univ, of Calif., Berkeley, 1972.

7. Tsai, N. C., Niefoff, D., Swatta, M., and Hadjian, A. H., "The Use of Frequency-Independent Soil-Structure Interaction Parameters, "Nuclear Engineering \& Design, Vol. 31, 1974, pp. 168-183.

8. Richart, Jr., F. E., Hall, Jr., J. R., and Woods, R. D., Vibration of Soils and Foundations, Prentice Hall, Inc., 1990, pp. 347 and 382.

9. Luco, J. E., "Vibrations of a Rigid Disc on a Layered Viscoelastic Medium," Nucl ear Eng. \& Design, Vol. 36, 1976, pp. 325-340.

10. Kausel, E. and Roesset, J. M., "Dynamic Stiffness of Circular Footings," Jour. Eng. Mech. Div., ASCE, Vol. 101, No. EN6, Dec. 1975, pp. 771-785.

11. Novak, M., "Vibrations of Embedded Footings and Structures," Preprint \#2029, ASCE Nat. Struct. Eng. Meeting, San Francisco, Calif., April 9-13, 1973.

12. Tsai, N. C., A Discussion of Agrawal's Paper: "Comparative Study for Soii-Structure Interaction Effect by the Soil Spring and Finite Element Model, "Technical Paper, Bechtel Power Corporation, San Francisco, Calif., Det., 1973.

is. Tsai, N. C., "Modal Damping for Soil-Structure Interaction," Jour. Eng. Mech. Div., ASCE, Vol. 100, No. EY2, April 1974, pp. 323-341. 
14. Roesset, J. M., Dobry, R., atd Whitwan, R. V., "Modal Analysis for Structures with Foundation Interaction," Jour, Struct. DiV., ASCE, Vol. 99, No. ST3, March 1973.

15. Whitman, B. W., "\$oil-Structure Interaction," Selsmic Design for Huclear Power Plants, R. J. Hansen, ed., MIT Press, Cambridge, Mass., 1970, pD. $241-269$.

16. Whi tman, R. V., Protonotarios, J. N., and Nelson, M. F+, "Case Study of Soil-Structure Interaction, "Presented at 0ot. 16-22, 1972 ASCE Amual \& National Invíronmental Engineering Meeting, Houston, Texas, Preprint $\$ 1816$.

17. Mizuno, K. and Isushima, Y., "Experimental and Analytical Studies for a Bith Nuclear Heactor Building Evaluation of Soil-Structure Interaction Behavior," Proc. 3rd SMiRT Conf., London, 1975, Paper $13 / 2$.

19. Tajimi, H., "Interaction of Building and Grownd," Earthg. Eng., Nov. 1968, Shokokusha Publishing co.

19. Mizuno, N., Moribe, T., Suziyame, N., Tsushima, Y., Kushida, H., and Tamabi, T., "Forced Vibcation Test of Bkl Type Nuclear Reactor Buildings Considering Through Soil Coupling Between Adjacent Buildings," Proc. 5th SMIRT Conf, Berila, August, 1979, Paper $k 13 / 4$.

20. Hirasawa, M., Okajima, S., and Satoh, K., "Dphamic Rehavior of a Nuciear Reactor Building," Proc. 4th SMIRT Conf., San Francisco, Calif., Aug. 1977.

21. Appendix 3.7c, Soil-Structure Interaction Parameters, Development of Soil Structure Intraption Parameters for Proposed Units 2 and 3, San onofre Generation Station for Southern California Edison Co., by Woodward, Moleill \& Assoe., Jan. 31, 1971, final Rev.

22. Novak, M., "Prediction of Footing Vibrations," Jour. Soil Mech. Div, ASCE, Vol. 95, Na. SM3, May 1970. 